\title{
Discovery of pluripotency-associated microRNAs in rabbit preimplantation embryos and embryonic stem-like cells
}

\author{
Pouneh Maraghechi, László Hiripi, Gábor Tóth, Babett Bontovics, Zsuzsanna Bósze \\ and Elen Gócza \\ Applied Embryology and Stem Cell Research Group, Institute for Animal Biotechnology, Agricultural Biotechnology \\ Center, Szent-Györgyi Albert Street 4, Gödöllö 2100, Hungary \\ Correspondence should be addressed to E Gócza; Email: elen@abc.hu
}

\begin{abstract}
MicroRNAs (miRNAs) are small non-coding RNAs that regulate multiple biological processes. Increasing experimental evidence implies an important regulatory role of miRNAs during embryonic development and in embryonic stem (ES) cell biology. In the current study, we have described and analyzed the expression profile of pluripotency-associated miRNAs in rabbit embryos and ES-like cells. The rabbit specific ocu-miR-302 and ocu-miR-290 clusters, and three homologs of the human C19MC cluster (ocu-miR-512, ocu-miR-520e, and ocu-miR-498) were identified in rabbit preimplantation embryos and ES-like cells. The ocu-miR-302 cluster was highly similar to its human homolog, while ocu-miR-290 revealed a low level of evolutionary conservation with its mouse homologous cluster.

The expression of the ocu-miR-302 cluster began at the 3.5 days post-coitum early blastocyst stage and they stayed highly expressed in rabbit ES-like cells. In contrast, a high expression level of the ocu-miR-290 cluster was detected during preimplantation embryonic development, but a low level of expression was found in rabbit ES-like cells. Differential expression of the ocu-miR-302 cluster and ocu\scale $100 \%$ \{miR-512 miRNA was detected in rabbit trophoblast and embryoblast. We also found that Lefty has two potential target sites in its $3^{\prime}$ UTR for ocu-miR-302a and its expression level increased upon ocu-miR-302a inhibition. We suggest that the expression of the ocu-miR-302 cluster is characteristic of the rabbit ES-like cell, while the ocu-miR-290 cluster may play a crucial role during early embryonic development. This study presents the first identification, to our knowledge, of pluripotency-associated miRNAs in rabbit preimplantation embryos and ES-like cells, which can open up new avenues to investigate the regulatory function of ocu-miRNAs in embryonic development and stem cell biology.

Reproduction (2013) 145 421-437
\end{abstract}

\section{Introduction}

MicroRNAs (miRNAs) are $\sim 22 \mathrm{nt}$ non-coding RNAs implicated in the regulation of multiple biological processes including development, differentiation, and oncogenesis (Bartel 2004). miRNAs regulate posttranscriptional gene expression, mostly through binding to complementary regions within $3^{\prime} U T R$ s of their target mRNAs, leading to translational repression or cleavage (Lim et al. 2005).

Regulation of gene expression in developmental processes is an important aspect of miRNA function. The first identified miRNAs, termed lin-4 and let-7, were found to be critical for the temporal control of larval development in Caenorhabditis elegans (Wightman et al. 1993, Reinhart et al. 2000). Many experiments have been performed to dissect the miRNA pathway in various organisms, demonstrating that miRNAs are essential for proper embryonic development. In C. elegans, dcr-1 homozygous mutant worms, in addition to being sterile, have shown some partially penetrant developmental abnormalities, such as egg-laying defect (Egl) and burst vulva phenotypes (Grishok et al. 2001, Ketting et al. 2001). Dicer-deficient mice die very early in development, by embryonic day 7.5, with essentially the arrest of development prior to gastrulation and the depletion of the pluripotent state (Bernstein et al. 2003). In addition, Dicer $^{\text {ex } 1 / 2}$ (deletion of the first and second exons of the Dicer gene) homozygous mouse embryos are severely hypomorphic, display a retarded phenotype, and die mid-gestation (Yang et al. 2005). Recent studies have demonstrated the embryonic-stage-specific expression of miRNAs (Mineno et al. 2006). Interestingly, several stem-cell-specific miRNAs such as the miR-290 cluster have been shown to be the first de novo-expressed miRNAs in mouse embryos at the 2-4-cell stage, with an increasing expression through the blastocyst stage (Zeng \& Schultz 2005, Tang et al. 2007, Viswanathan et al. 2009, Svoboda \& Flemr 2010). Moreover, miR-290 cluster deficiency in mouse embryos causes penetrant embryonic lethality and germ cell defects, implying the 
important role of this cluster in embryonic development (Medeiros et al. 2011).

miRNAs have also been identified as important regulators of embryonic stem cell (ESC) properties (Cao et al. 2008, Gu et al. 2008, Marson et al. 2008). Dicermutant mouse ESC lines expressing pluripotent markers have shown a pronounced proliferation defect, the failure of teratoma and chimera formation, and the loss of differentiation ability (Kanellopoulou et al. 2005, Murchison et al. 2005). Dgcr8-knockout mouse ESCs have an extended population doubling time and a defect in embryonic body and teratoma formation (Wang et al. 2007b). In addition to the Dicer- and Dgcr8-mutant ESC analyses that allow an overall investigation of the function of the miRNA pathway in ESCs, cloning and deep sequencing of miRNAs from stem cells have revealed the identity of ESC-specific miRNAs that may function in ESC self-renewal and differentiation. The mmu-miR-290 cluster has been reported as an ESCspecific miRNA that was highly expressed in undifferentiated ESCs (Houbaviy et al. 2003) and inhibited ESC differentiation (Zovoilis et al. 2009). This cluster has an important regulatory function in undifferentiated ESCs through the direct control of de novo DNA methylation (Benetti et al. 2008, Sinkkonen et al. 2008) and cell cycle regulation by suppressing the G1-S transition and targeting cell cycle regulators (Wang et al. 2008, Lichner et al. 2011), and also modulates pluripotency through the repression of the canonical NF- $\kappa \mathrm{B}$ pathway (Luningschror et al. 2012). In addition, the promoter of this cluster is a direct target of key ESC transcription factors, such as OCT4, SOX2, and NANOG (Marson et al. 2008). The human homolog of the mmu-miR-290 cluster, the miR-371 cluster, was also shown to be expressed in human ESCs (Suh et al. 2004) and did not reappear in any somatic lineage (Strauss et al. 2006). This cluster shares the chromosomal region with the chromosome 19 miRNA cluster (C19MC cluster), which is a highly repetitive region containing 46 members of the superfamily and shows high sequence similarity to both hsa-miR-371 and mmu-miR-290 clusters (Bentwich et al. 2005, Lichner et al. 2011). The miR-302 cluster is also highly expressed in both human and mouse ESCs and downregulated upon differentiation (Chen et al. 2007). Similar to the miR-290 family, this cluster is a cell cycle regulator; cyclin D1 and Cdk4 are post-transcriptionally regulated by the miR-302 cluster in human ESCs, resulting in the positive regulation of ESC self-renewal (Card et al. 2008). Furthermore, this cluster might positively regulate the Nodal/Activin pathway, therefore contributing to the maintenance of pluripotency (Barroso-delJesus et al. 2009). The miR-302 gene cluster is itself a downstream transcriptional target of NANOG, OCT3/4, REX1, and SOX2 (Barroso-delJesus et al. 2008, Card et al. 2008).

Apart from miRNA's role in ESC maintenance, recent reports have described the emerging role of miRNAs in somatic cell reprogramming (Judson et al. 2009, Anokye-Danso et al. 2011, Li et al. 2011, Liao et al. 2011, Lin et al. 2011, Miyoshi et al. 2011, Subramanyam et al. 2011, Yang et al. 2011, Kelley \& Lin 2012), which has also been discussed in several review papers (Kuo et al. 2012, Li \& He 2012, Lipchina et al. 2012). The first study showed that c-Myc replacement of Yamanaka factors (Takahashi \& Yamanaka 2006) by individual members of the miR-290 family enhances the reprogramming of mouse somatic cells to an induced pluripotent stem cell (iPSC) state (Judson et al. 2009). A most recent report has indicated that iPSCs can be generated even more efficiently using lentiviral-based expression of the miR-302 cluster from both human and mouse somatic cells (Anokye-Danso et al. 2011). Interestingly, mouse and human cells can be reprogrammed to an iPSC state even by the direct transfection of mature double-stranded miRNAs with no requirement for vector-based gene transfer (Miyoshi et al. 2011). It is still not clear whether miRNAs alone can replace Yamanaka reprogramming factors; however, miRNAs can enhance reprogramming by promoting cell-cycle progression (Wang et al. 2008, Li et al. 2011) and also by suppressing Tgfb signaling to promote the mesenchymalto-epithelial transition (Li et al. 2011, Subramanyam et al. 2011). Furthermore, miRNAs can also enhance the stemness and pluripotency of reprogrammed somatic cells at later stages. miR-302 miRNAs (miR-302s) can trigger global genomic DNA demethylation by the co-suppression of epigenetic regulators such as AOF2, AOF1, MECP1-p66, and MECP2 and subsequently promote the reactivation of pluripotency-associated genes, particularly POU5F1 (OCT4), SOX2, and NANOG (Lin et al. 2011).

In the context of biomedical research, precise genetic engineering in rabbits (Oryctolagus cuniculus) would be a valuable model to generate genetically defined rabbit models of human diseases. To date, the rabbit has been applied as an experimental model of atherosclerosis, Alzheimer's disease, eye research, osteoarthritis, tuberculosis, and diabetes (Narayanaswamy et al. 2000, Lin et al. 2007, Winiarska et al. 2008, Woodruff-Pak 2008, Ramin et al. 2010, Zahn et al. 2010, Kang \& Grossniklaus 2011, Thieme et al. 2012), as well as transgenesis for the production of pharmaceutical proteins (Hiripi et al. 2003, Baranyi et al. 2007, Ripplinger et al. 2007, Han et al. 2008). The first liveborn ES-derived rabbit chimera has been reported in 2010, albeit not with high efficiency (Zakhartchenko et al. 2011). Therefore, rabbit ESCs (rabESCs) would be an invaluable tool for both creating second-generation transgenic models of human diseases and testing stem cell therapies for human applications. Although several groups could generate rabESCs with different derivation methods (Wang et al. 2007a, Catunda et al. 2008, Honda et al. 2008, 2009, Intawicha et al. 2009), they is still difficult to establish and remain poorly 
characterized. Since ECSs are derived from early blastocysts, they can reflect the potential characteristic of their founder embryonic population. Therefore, it is important to compare the expression pattern of both miRNAs and proteins that are known to play regulatory roles during early lineage specification.

Collectively, we aimed to explore the ESC-specific miRNA expression pattern using the SOLiD System Small RNA Analysis from early embryonic stages to early rabbit ES-like cell passages for the first time to get more insight into their potential regulatory mechanism in embryonic development and tuning stem cell properties.

\section{Results \\ SOLiD small RNA CDNA library sequencing}

To evaluate miRNA expression at the early cell-fate decision steps of the rabbit embryo, we chose to determine the expression of rabbit-specific miRNAs (ocu-miRNAs) at different embryonic stages. We sequenced a small RNA library constructed with the SOLiD small RNA expression kit from the total RNA of 6 and 7 days post-coitum (dpc) rabbit embryos and a Carnegie stage 17 embryo ( $14 \mathrm{dpc})$, germinal ridges containing primordial germ cells (PGCs) from $14 \mathrm{dpc}$ embryos (mixed male and female), and rabbit embryonic fibroblast (rabEF) as a control. The expression of pluripotency associated miRNAs during early embryonic stages may reflect the ability of pluripotent cells to give rise to ES cells. Therefore, we also sequenced a small RNA library of rabbit ES-like cells and mouse embryonic fibroblast (MEF) cells that were used as a feeder layer for rabbit ES-like cell cultivation.

Massively parallel sequencing of amplified cDNA fragments using the SOLiD 3 System generated 2664988, 901107, 3015131, 2551138, 2045460, 3049402 , and 2448960 sequence reads corresponding to rabbit $6 \mathrm{dpc}, 7 \mathrm{dpc}, 14 \mathrm{dpc}$, PGCs, rabbit ES-like cells, rabEF, and MEF respectively (Supplementary Figure 1, see section on supplementary data given at the end of this article). To analyze the sequence data, we identified sequence matches to known human, mouse, and bovine miRNAs (hsa-miRNAs, mmu-miRNAs, and bta-miRNAs) in miRBase, representing $5.4 \%$ of $6 \mathrm{dpc}$ embryo reads, $15.8 \%$ of $7 \mathrm{dpc}$ embryo reads, $35.0 \%$ of $14 \mathrm{dpc}$ embryo reads, and $16.6 \%$ of rabES-like cell reads to the known hsa-miRNA database, and $7.6 \%$ of $6 \mathrm{dpc}$ embryo reads, $21.7 \%$ of $7 \mathrm{dpc}$ embryo reads, $46.2 \%$ of $14 \mathrm{dpc}$ embryo reads, and $27.1 \%$ of rabES-like cell reads to the known mmu-miRNA database (supplementary details are provided in Supplementary Table 1). A total of 80, 199, and 246 known hsa-miRNAs, mmu-miRNAs, and btamiRNAs were identified to be expressed in rabbit $6 \mathrm{dpc}$ and $7 \mathrm{dpc}$ embryos and rabbit ES-like cells respectively (more data are provided in Supplementary Figure 2). We defined similarity of the obtained ocu-miRNAs to the known hsa-miRNAs, mmu-miRNAs, and bta-miRNAs as the fraction of all expressing rabbit miRNAs that corresponds to hsa-miRNAs, mmu-miRNAs, and btamiRNAs respectively. Thus, ocu-miRNAs exhibited more similarity to the known hsa-miRNAs than to the known mmu-miRNAs and bta-miRNAs. The identified ocu-miRNAs in 6 and 7 dpc rabbit embryos were 69 and $81 \%$ similar to hsa-miRNAs compared with the lower similarity of 61 and $70 \%$ to mmu-miRNAs and 66 and $62 \%$ to bta-miRNAs respectively. Likewise, rabbit miRNAs of 14 dpc embryos, PGCs, and rabEF showed more similarity to hsa-miRNAs. However, the miRNAs of rabbit ES-like cells displayed slightly more similarity to mmu-miRNAs (71\%) than to hsa-miRNAs $(69 \%)$, which can be explained by impurities associated with feeder layer usage during cell culture (Fig. 1A). We also identified the number of similar ocu-miRNAs to each set of known hsa-miRNAs, mmu-miRNAs, and btamiRNAs. Out of 80 ocu-miRNAs expressed in $6 \mathrm{dpc}$ embryos, 33 were identified in all four species, 14 were matched to hsa-miRNAs, 9 to mmu-miRNAs, and 13 to bta-miRNAs. From 199 expressing ocu-miRNAs in 7 dpc embryos, 37 were similar to hsa-miRNAs, 20 to mmumiRNAs, and 16 to bta-miRNAs, with 98 miRNAs shared by all four species. Rabbit ES-like cells that expressed 246 ocu-miRNAs presented 40 similar miRNAs to hsamiRNAs, 45 miRNAs to mmu-miRNAs, and 27 miRNAs to bta-miRNAs with 108 miRNAs in common (Fig. 1B).

From more than 14 million miRNA high-quality reads obtained from the constructed rabbit small RNA library, we could identify a total of 1693 expressed rabbitspecific miRNAs representing greater similarity to known hsa-miRNAs. The number of reads obtained reflected the relative abundance and expression levels of miRNAs. Among the frequently sequenced miRNAs, we chose to analyze pluripotency associated miRNAs in rabbit ES-Like cells and during early embryogenesis.

\section{Mature and putative pre-miRNA structure of rabbit miR-302 and miR-290 clusters}

The polycistronic cluster of miR-302 that is located on human chromosome 4 consists of ten mature miRNAs: miR-302a-3p, miR-302a-5p, miR-302b-3p, miR-302b$5 p, \quad$ miR-302c-3p, miR-302c-5p, miR-302d-3p, miR-302d-5p, miR-367-3p, and miR-367-5p (Houbaviy et al. 2003, Suh et al. 2004). The murine homolog of the miR-302 cluster is located on chromosome 3 and presents all ten mature miRNAs. However, only the $-3 p$ mature miRNAs have been annotated until now in cattle (Strozzi et al. 2009). The mouse miR-290 cluster on chromosome 7 has a single spliced primary transcript, generating 14 mature miRNAs: miR-290-5p, miR-290-3p, miR-291a-5p, miR-291a-3p, miR-291b-5p, miR-291b3p, miR-292-5p, miR-292-3p, miR-293-5p, miR-293-3p, miR-294-5p, miR-294-3p, miR-29-5p, and miR-295-3p (Houbaviy et al. 2003, 2005). miR-292 is the only 
A

ocu-miRNA similarity to hsa $\%, \mathrm{mmu} \%$, and bta\%.

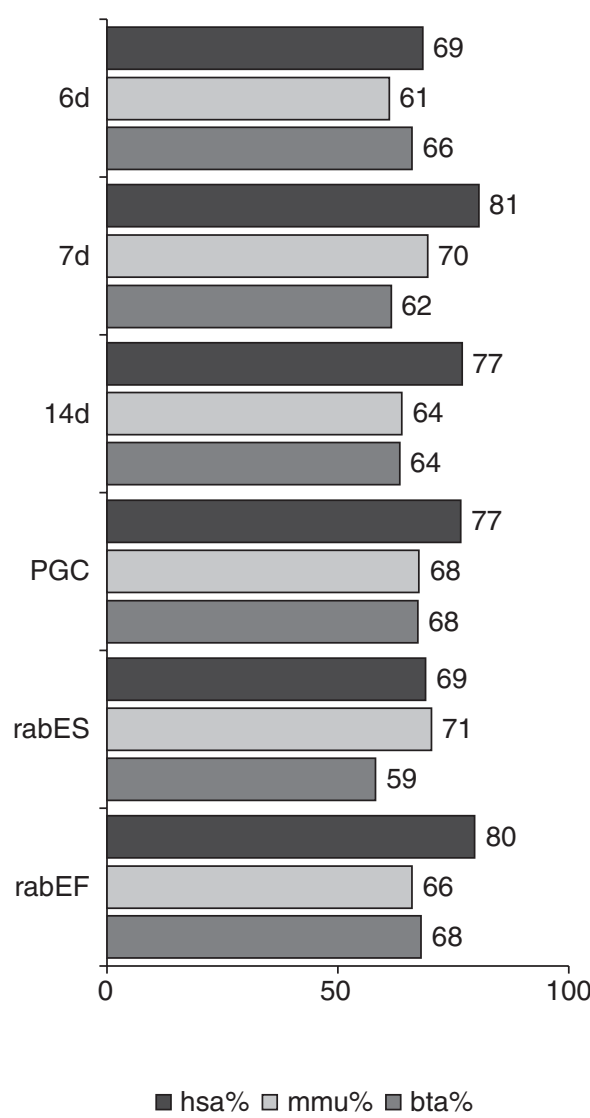

B

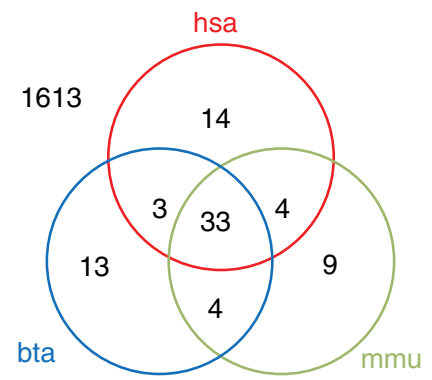

$6 d$

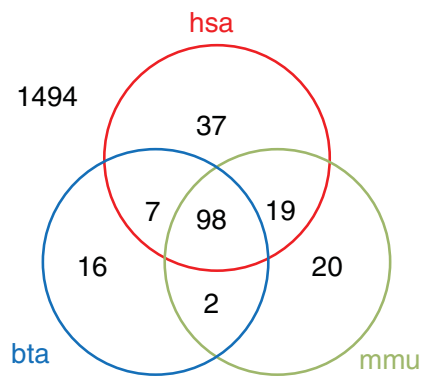

$7 d$

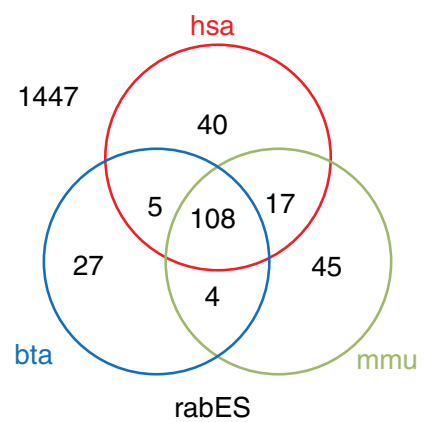

Figure 1 Similarity of rabbit specific miRNAs to human (hsa), mouse (mmu), and bovine (bta) miRNAs. (A) Percentage of all expressing rabbit miRNAs corresponding to known hsa-miRNAs, mmu-miRNAs, and bta-miRNAs is shown. The number of expressing rabbit miRNAs was determined as those represented by at least ten sequencing reads. Calculation was carried out for each embryo stage or cell type separately. The similarity of all the identified ocu-miRNAs was higher to the known hsa-miRNAs than to mmumiRNAs and bta-miRNAs. However, rabbit ES-like cells displayed slightly higher similarity to mmumiRNAs $(71 \%)$ than to hsa-miRNAs $(69 \%)$, which was due to impurities associated with feeder layer (MEF) usage during cell culture. $6 \mathrm{~d}, 6 \mathrm{dpc}$ rabbit embryo; 7d, 7 dpc rabbit embryo; 14d, $14 \mathrm{dpc}$ rabbit embryo; PGC, germinal ridges containing primordial germ cells of $14 \mathrm{dpc}$ rabbit embryo; rabES, rabbit embryonic stem-like cells; rabEF, rabbit embryonic fibroblast. (B) Venn diagrams illustrating the overlaps between the number of miRNAs expressed in the rabbit with hsa-miRNAs, mmu-miRNAs, and bta-miRNAs and the numbers of ocu-miRNAs similar to hsa-miRNAs, mmumiRNAs, and bta-miRNAs. $6 \mathrm{~d}, 6 \mathrm{dpc}$ rabbit embryo; 7d, 7 dpc rabbit embryo; rabES, rabbit embryonic stem-like cells; hsa, hsa-miRNAs; mmu, mmu miRNAs; bta, bta-miRNAs. annotated member of this cluster in cattle (Strozzi et al. 2009). The human homolog of the mmu-miR-290 cluster, the miR-371 cluster, which is located on chromosome 19, is also expressed in human ESCs (Houbaviy et al. 2003, Suh et al. 2004, Laurent et al. 2008). This miRNA cluster shares this chromosomal region with the C19MC cluster, which is a highly repetitive region with 46 tandem repeats and is the largest hsa-miRNA gene cluster, expressed in placental tissues and human ESCs (Bentwich et al. 2005, Bar et al. 2008, Cao et al. 2008, Bortolin-Cavaille et al. 2009). To analyze the mature structure of rabbit miRNA clusters, we performed a local alignment using the UCSC Genome Rabbit BLAT Search by comparing mature miRNA query sequences obtained from the SOLiD small RNA analysis with the rabbit genome assembly. The miR302 gene cluster was identified on the positive strand of rabbit chromosome 15 in the same order as observed in human, mouse, and bovine clusters. At the mature sequence level, seven miRNAs showed $100 \%$ identity to human mature miRNAs, while ocu-miR-302a-5p, ocumiR-302b-3p, and ocu-miR-302b-5p had 95.8, 95.7, and $95.4 \%$ identity respectively. In contrast, similarity to
mmu-miRNAs and bta-miRNAs was slightly lower (Supplementary Table 2, see section on supplementary data given at the end of this article). They all share the same AAGTGCT and CTTTAAC seed sequences with human, mouse, and bovine homologs. However, ocumiR-367 has a different seed sequence (ATTGCA) from its human and mouse homologs. Detailed information about mature miRNAs of the rabbit miR-302 cluster is shown in Supplementary Table 3. Despite the high similarity of the rabbit ocu-miR-302 cluster to its human homolog, the ocu-miR-290 cluster exhibited lower similarity to the mouse cluster. Rabbit homologs of the mmu-miR-290 cluster were located on the reverse strand of a short pseudo-chromosome chrUn0226 (scaffold GL018924). Among 14 members of the mouse cluster, rabbit ocu-miR-290-5p, ocu-miR-292-3p, and ocu-miR294-3p presented $90.9,87.5$, and $100 \%$ identity to their mouse mature miRNA homologs at the mature sequence level respectively (Supplementary Table 4). Interestingly, ocu-miR-294-3p was also found on chromosome 2 by the mature sequence analysis with an identity of $90.9 \%$ on this locus. Furthermore, the homologs of mir-512-5p, miR-512-3p, miR-498, and miR-520e of the human 
C19MC cluster were all represented in the rabbit but we could not identify the rabbit homolog of the miR-371 cluster. We found two repeats of rabbit ocu-miR-512-5p and ocu-miR-512-3p located $5^{\prime}$ to the rabbit miR-290 cluster on the reverse strand of chrUn0226. At the mature sequence level, ocu-miR-512-5p repeats displayed 82.6 and $78.2 \%$ (ocu-miR-512-I-5p and ocumiR-512-II-5p respectively) identity to the human homologs. Both repeats of ocu-miR-512-3p, which were located within $2.8 \mathrm{~kb}$ of each other, displayed $72.2 \%$ identity to their human homologs. Rabbit miR498 and miR-520e exhibited 82.6 and $95.2 \%$ identity to their human homologs (Supplementary Table 4). Details of the mature miRNA sequences and chromosomal positions are provided in Supplementary Table 5.

In order to confirm the mature sequence of rabbit miR290 cluster members, a rabbit BAC library, created and maintained by Rogel-Gaillard et al. (2001), was screened using ocu-miR-290, ocu-miR-294, and ocu-Nlrp12 (NLR family, pyrin domain containing 12: upstream gene of the miR-290 gene cluster) primers. A rabbit BAC clone 566F12 that harbors rabbit miR-290 cluster members was identified. The mature sequence of rabbit miR-290 cluster members obtained through BAC sequencing confirmed the result of the local alignment of the rabbit genome assembly. The chromosomal localization of this BAC clone is still unknown.

To identify the putative secondary structure of rabbitspecific miRNAs, a local BLAST search was performed using their human and mouse pre-miRNA homologs as query sequences. Since the mature miRNA sequences of the ocu-miR-302 cluster showed the highest similarity to their human homologs, the predictive secondary structure of this cluster was obtained based on the local alignment of human miR-302 cluster pre-miRNA query sequences against the rabbit genomic sequence. The identity of ocu-miR-302a, ocu-miR-302b, ocu-miR302c, ocu-miR-302d, and ocu-miR-367 was 98.5, 85, $100,95.5$, and $98.6 \%$ to their human pre-miRNA homologs respectively. Secondary structures of the ocu-miR-290 cluster were acquired using the local alignment of pre-miRNA sequences of the mouse miR290 cluster against the rabbit genomic sequence.
Despite the low degree of similarity of rabbit premiRNA sequences to their mouse homologs, we could predict the putative secondary structure of ocu-miR-290 cluster members. Surprisingly, ocu-miR-290-5p and ocu-miR-292-3p formed a single pre-miRNA, which we named as ocu-miR-290/292 pre-miRNA (Supplementary Figure 3, see section on supplementary data given at the end of this article). The pre-miRNA sequences of ocu-miR-512, ocu-miR-498, and ocumiR-520e located 7594 nt upstream to the ocu-miR290 cluster were obtained based on the local alignment of their human homologs against the rabbit genomic sequence. The ocu-miR-512 precursor had two repeats differed by only one base in their $5^{\prime}$ end of the mature sequence and three bases in their $3^{\prime}$ end of the pre-miRNA sequence. Afterwards, candidate rabbit pre-miRNAs were folded with RNAshapes software. Pre-miRNAs with minimum free energy (MFE) were selected as the putative secondary structure. The structures and detailed information for candidate pre-miRNAs are shown in Supplementary Figure 3.

\section{Putative binding sites of transcription factors within the promoter region of rabbit miRNA families}

A highly conserved region of $525 \mathrm{bp}$ upstream to the transcriptional start of the miR-302 gene cluster has been demonstrated to be a core promoter region of this gene cluster in human ESCs, which is regulated by ESCassociated transcription factors including OCT4, NANOG, SOX2, and REX1 (Barroso-deljesus et al. 2008). In order to identify the putative binding sites of ESC-associated transcription factors in the rabbit, we performed a local alignment analysis by comparing predicted transcription factor binding sites within the human ESC core promoter region (Barroso-delJesus et al. 2008, Card et al. 2008) with the rabbit genome assembly. We identified Oct4, Sox2, and Nanog binding sites in the putative promoter region of the ocu-miR-302 cluster located on chromosome 15, which are conserved regions in humans and mice and also in other species such as primates, other mammals, and birds (Fig. 2). We could not detect the core promoter region of the

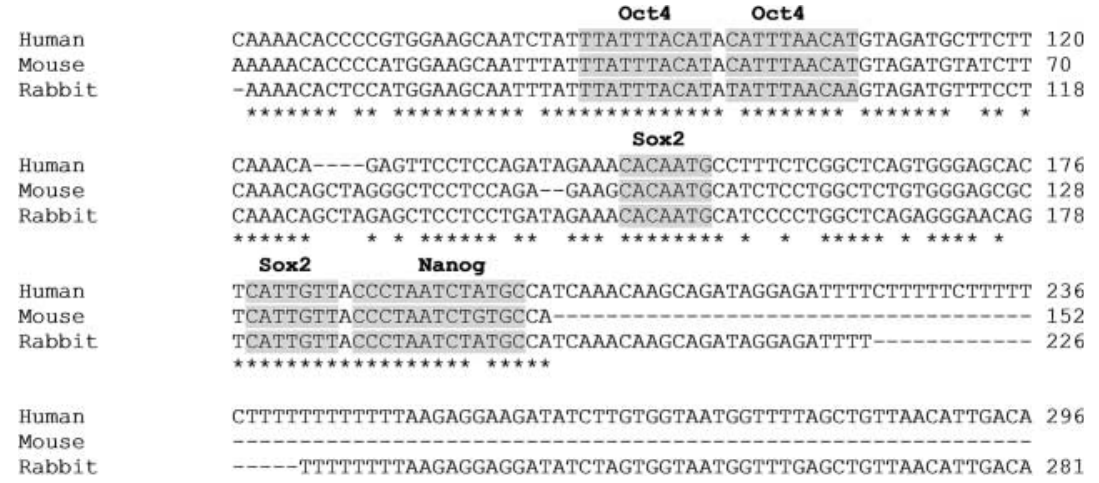

www.reproduction-online.org
Figure 2 Putative binding sites of Oct4, Sox2, and Nanog to the promoter region of the ocu-miR-302 cluster. Alignment of the homologous promoter regions of the miR-302 cluster of miRNAs from rabbits, humans, and mice. The consensus Oct4, Sox2, and Nanog transcription factor binding sites are highlighted in gray. The asterisks indicate sequence homology. 

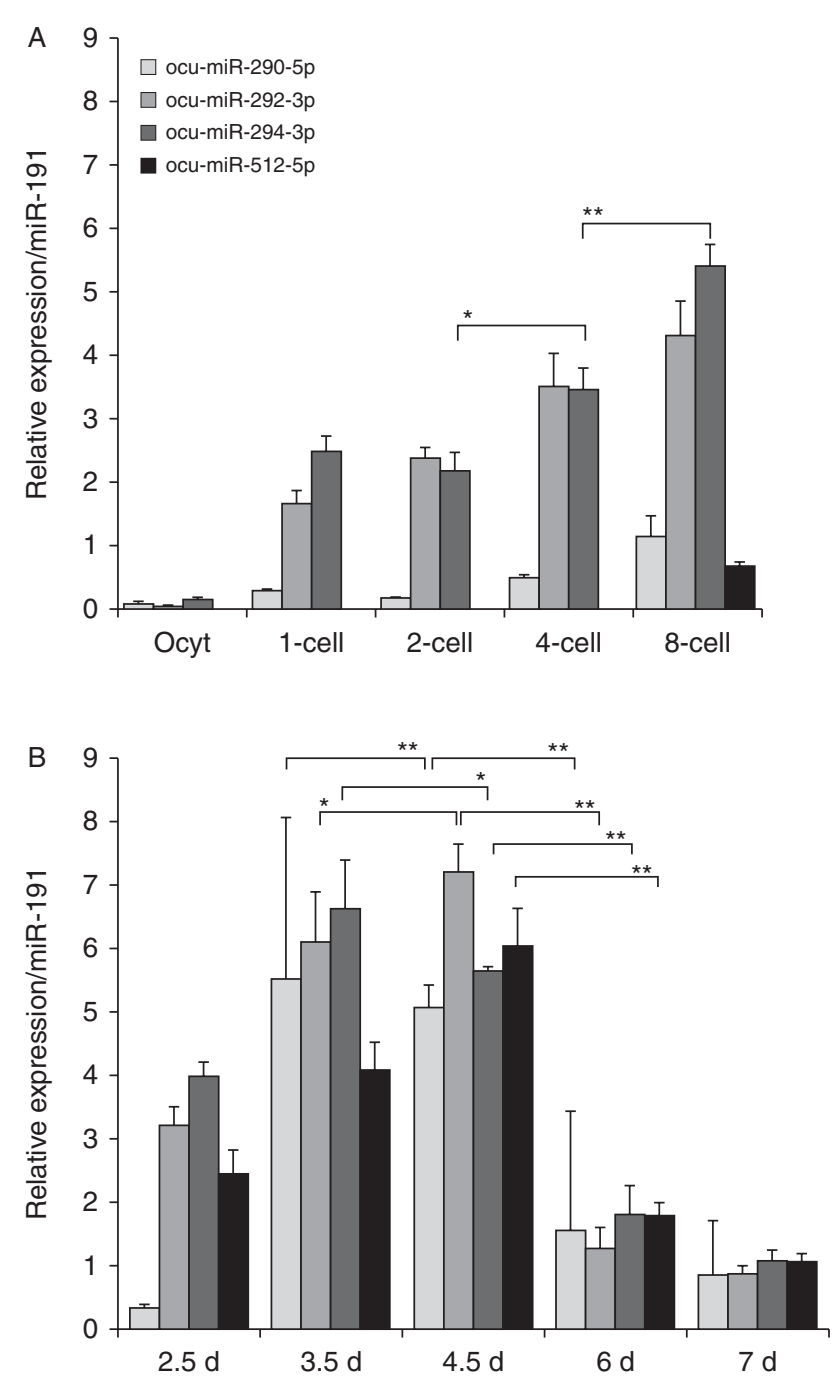

Figure 3 Rabbit miR-290 cluster and miR-512 are expressed in early embryonic stages. (A) Quantitative real-time PCR analysis showed that the expression of ocu-miR-290 family members began in the 4-cellstage rabbit embryos; however, the expression of ocu-miR-512-5p started later, in the 8-cell-stage rabbit embryos. (B) ocu-miR-290 family expression increased stepwise up to the $3.5 \mathrm{dpc}$ blastocyst stage and was downregulated in the $6 \mathrm{dpc}$ embryos. ocu-miR-512-5p displayed a gradual increase in the expression level up to $4.5 \mathrm{dpc}$ embryos and downregulated at the $6 \mathrm{dpc}$ stage. Ocyt, oocytes; 1 -cell, 1-cell-stage embryos; 2-cell, 2-cell-stage embryos; 4-cell, 4-cell-stage embryos; 8-cell, 8-cell-stage embryos; $2.5 \mathrm{~d}, 2.5 \mathrm{dpc}$ embryos; $3.5 \mathrm{~d}, 3.5 \mathrm{dpc}$ embryos; 4.5d, 4.5 dpc embryos; 6d, 6 dpc embryos; $7 d, 7$ dpc embryos. Expression levels were calculated relative to ocu-miR-191-5p and normalized to the $7 \mathrm{dpc}$ miRNA level. The asterisks indicate statistically significant differences: ${ }^{*} P<0.05 ;{ }^{* *} P<0.02$.

ocu-miR-290 family in the rabbit, perhaps because this family is located on a contig that is not yet assigned to a chromosome.

\section{miRNA expression during early rabbit embryonic development}

In order to acquire a comprehensive perspective of the stem-cell-specific miRNA expression level during early embryonic stages, miRNA expression in collected oocytes and early embryos at 1-cell, 2-cell, 4-cell, 8-cell, $2.5 \mathrm{dpc}$ (morula), $3.5 \mathrm{dpc}, 4.5 \mathrm{dpc}, 6 \mathrm{dpc}$, and $7 \mathrm{dpc}$ (blastocysts) was analyzed, using real-time RT-PCR analysis. The expression levels were calculated relative to ocu-miR-191-5p as a reference gene since it was expressed in nearly the same level in rabbit embryos, ES-like cells, and tissue samples based on the SOLiD small RNA and quantitative RT-PCR analysis. We observed an upregulation of the rabbit miR-290 family began at the 4-cell stage, and showed a steady increase up to the $3.5 \mathrm{dpc}$ blastocyst stage (Fig. 3). Each of the miR290 cluster members presented a low level of expression in oocytes. The miRNA level was higher in both 1 - and 2-cell-stage embryos compared with the level detected in
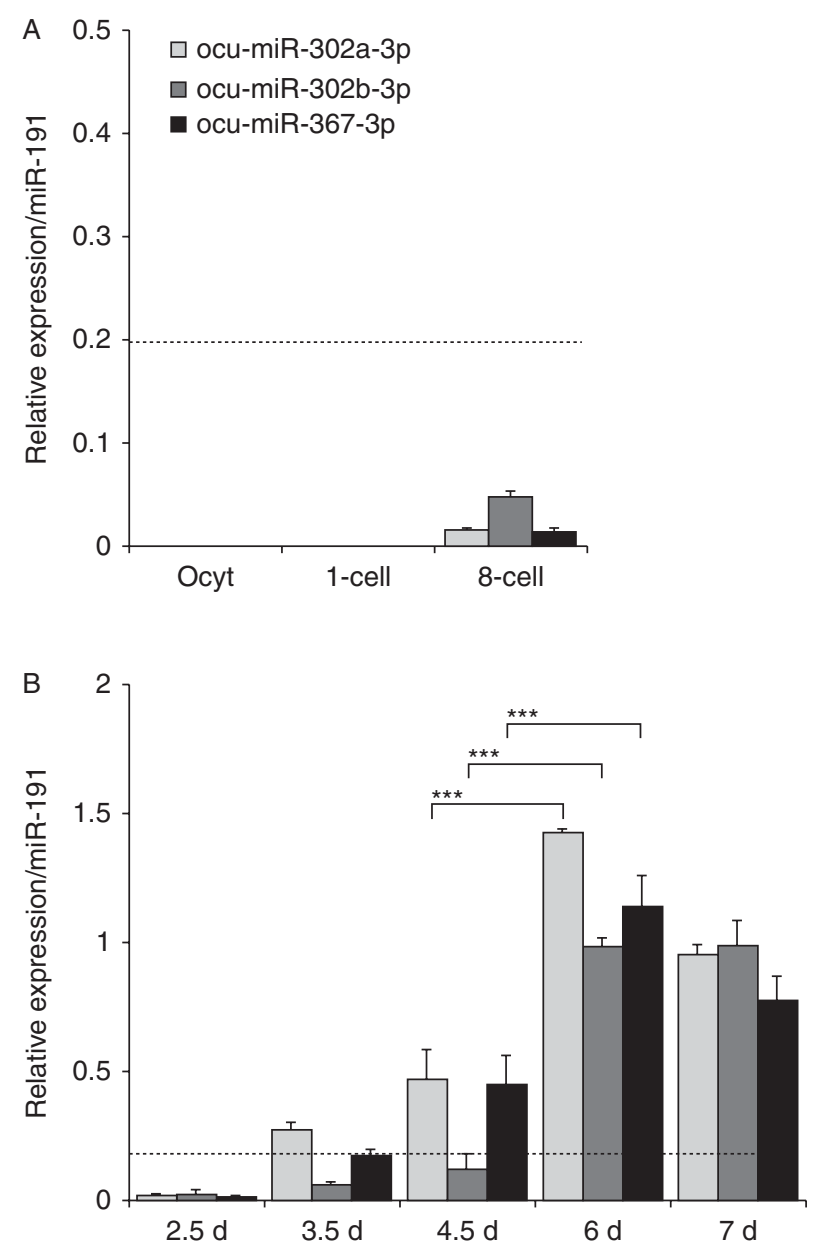

Figure 4 Rabbit mir-302 cluster displays a low expression level during early embryonic stages. (A) There was no considerable expression of the ocu-miR-302 cluster at early stages. (B) Expression of ocu-miR-302 began at the $3.5 \mathrm{dpc}$ stage and increased throughout embryonic development. Ocyt, oocytes; 1-cell, 1-cell-stage embryos; 8-cell, 8-cell-stage embryos; $2.5 \mathrm{~d}, 2.5 \mathrm{dpc}$ embryos; 3.5d, $3.5 \mathrm{dpc}$ embryos; 4.5d, 4.5 dpc embryos; 6d, 6 dpc embryos; 7d, 7 dpc embryos. Expression levels were calculated relative to ocu-miR-191-5p and normalized to the $7 \mathrm{dpc}$ miRNA level. The asterisks indicate statistically significant differences: ${ }^{* * *} P<0.001$. 
oocytes. The 4-cell-stage embryos compared with the 2-cell-stage embryos showed an increased expression level (about 2.8-fold change) of ocu-miR-290-5p. The ocu-miR-292-3p, and ocu-miR-294-3p expression levels in the 4-cell-stage embryos were 1.4- and 1.6-fold higher compared with the 2-cell-stage embryos (Fig. 3A). The expression of rabbit miR-290 family members increased stepwise throughout the following embryonic developmental stages up to the $3.5 \mathrm{dpc}$ blastocyst stage and was significantly upregulated at the $4.5 \mathrm{dpc}$ stage. The expression of ocu-miR-290-5p, ocu-miR-292-3p, and ocu-miR-294-3p were significantly downregulated at the 6 dpc stage by 3.3-, 5.7-, and 3.1-fold respectively. The expression levels in the 6 and $7 \mathrm{dpc}$ stage embryos were very similar (Fig. 3B). Notably, the expression of ocu-miR-512-5p was restricted to a narrow developmental stage-specific window, starting at the 8-cell stage with an extensively high fold change of 54 to the 4-cellstage embryos and gradually increased up to the $4.5 \mathrm{dpc}$ blastocyst stage. ocu-miR-512-5p presented a gradual increase in the expression level at the $4.5 \mathrm{dpc}$ stage and a substantial downregulation of 3.4-fold at the $6 \mathrm{dpc}$ stage, similar to rabbit miR-290 family members (Fig. 3A and B). In contrast to the rabbit miR-290 family, which was expressed in earlier embryonic stages, the rabbit miR-302 family began to express later at the $3.5 \mathrm{dpc}$ stage. The expression of ocu-miR-302 family members in rabbit oocytes and 1-cell-stage embryos was not detectable (Fig. 4A). There was no considerable expression in the 8-cell-stage and $2.5 \mathrm{dpc}$ embryos (Fig. 4A and B), whereas there was 13-, 2.4-, and 9.8-fold increases for ocu-miR-302a-3p, ocu-miR-302b-3p, and ocu-
m69iR-367-3p expression at the $3.5 \mathrm{dpc}$ blastocyst stage respectively, which could be considered as the reliable starting point for the expression of rabbit miR-302 cluster members. The expression level kept increasing up to $4.5 \mathrm{dpc}$; at $6 \mathrm{dpc}$, it increased by 3-, 7.9-, and 2.5-fold for ocu-miR-302a-3p, ocu-miR-302b-3p, and ocu-miR$367-3 p$ respectively (Fig. 4B). These results suggested that the miR-290 cluster might play a more significant role during early rabbit embryogenesis compared with the miR-302 cluster.

Furthermore, we analyzed the cell-specific expression of both ocu-miR-302 and ocu-miR-290 clusters in the trophoblast ( $\mathrm{Tr}$ ) and the embryoblast (Em) of a 6 dpc fully expanded blastocyst to examine whether there is a difference in the expression level of these embryonic cell types. While the expression levels of ocu-miR-290 cluster members were not significantly different among $\mathrm{Tr}$ and Em cells (Fig. 5A), the expression levels of ocumiR-302a-3p, ocu-miR-302b-3p, and ocu-miR-367-3p were 3.9-, 4.3-, and 2.6-fold higher in Em cells (Fig. 5B). The ocu-miR-512-5p miRNA was the only miRNA for which the expression level was higher in $\operatorname{Tr}$ cells (Fig. 5A). Moreover, we analyzed the ocu-miR-512-5p expression level in two cell layers of the Em (hypoblast and epiblast) in comparison with the $\operatorname{Tr}$ of $6 \mathrm{dpc}$ rabbit embryos to determine whether its expression is more related to a specific cell lineage. Interestingly, the expression of ocu-miR-512-5p was significantly higher in both $\operatorname{Tr}$ and hypoblast compared with the epiblast by 3- and 2.6-fold changes respectively (Fig. 5C).

In parallel with the miRNA expression analysis, the expression levels of stem cell markers (Oct4 and Nanog),
A

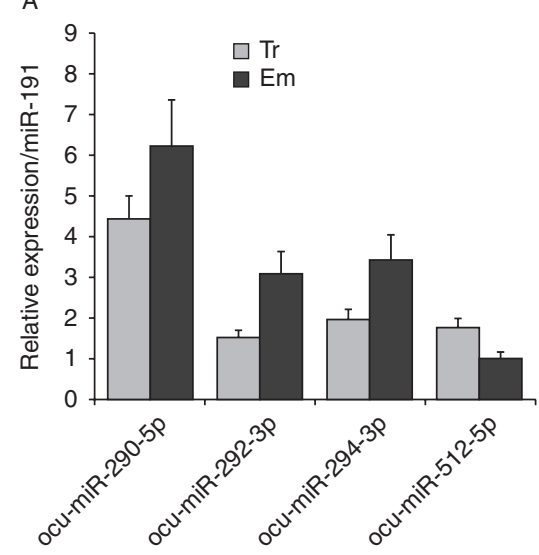

B

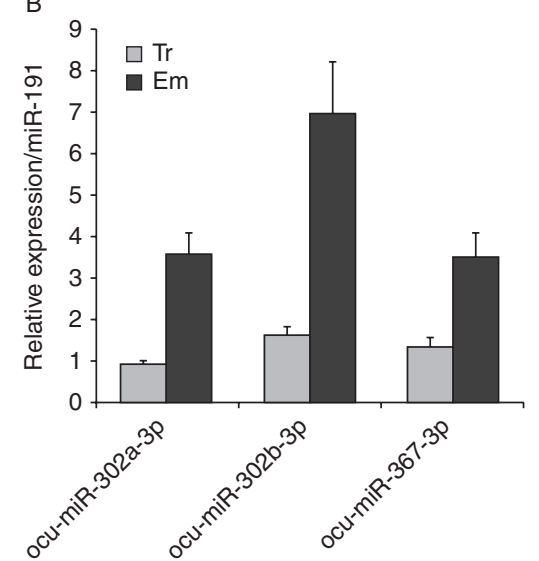

C

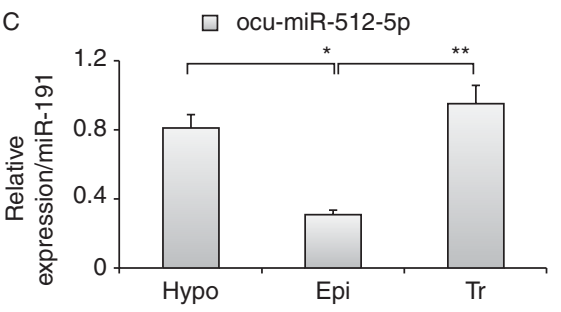

Figure 5 Cell-specific expression of rabbit miRNAs. (A) There was no significant difference in the expression of the ocu-miR-290 family between the trophoblast (Tr) and embryoblast (Em) cells in the 6 dpc stage embryos, while ocu-miR-512-5p expression was slightly high in the Tr. (B) The ocumiR-302 cluster was expressed at a markedly higher level in Em cells than in Tr cells. (C) The expression of ocu-miR-512-5p was significantly higher in both Tr and hypoblast (Hypo) compared with the epiblast (Epi). Expression levels were calculated relative to ocu-miR-191-5p and normalized to the $7 \mathrm{dpc}$ miRNA level in (B) and to the Tr miRNA level in (C). The asterisks indicate statistically significant differences: ${ }^{*} P<0.05 ;{ }^{*} P<0.02$. 
a Tr-specific transcription factor $(\mathrm{Cd} \times 2)$, and an early endodermal marker (Gata4) were evaluated by quantitative RT-PCR in rabbit embryos. Rabbit embryos expressed both stem cell and differentiation markers (Fig. 6). Rabbit oocytes contained maternal Oct4, Nanog, Cdx2, and Gata4 transcripts at a relatively low level. The 1-cell-stage embryos comprised maternal Oct4 and Gata4 transcripts, but Nanog and $\mathrm{Cdx} 2$ transcripts were not detected (Fig. 6A). The expression of Oct4, Nanog, and Cdx2 increased extremely in early blastocyst stage embryos ( $3.5 \mathrm{dpc}$ ) and kept increasing up to the $7 \mathrm{dpc}$ stage. The Gata 4 mRNA level was upregulated upon blastocyst expansion at the $6 \mathrm{dpc}$ stage and increased up to $7 \mathrm{dpc}$ (Fig. 6B). In addition, we
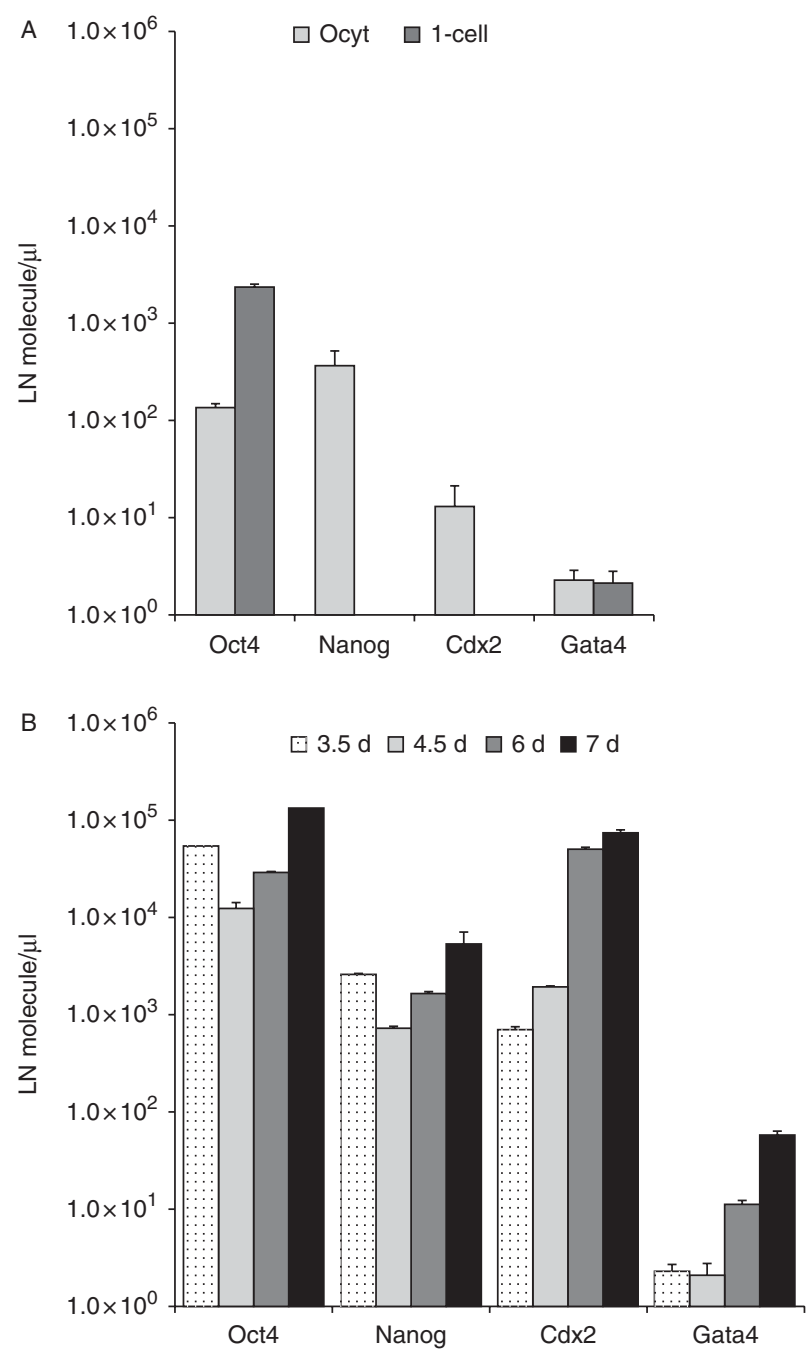

Figure 6 Quantitative RT-PCR analysis of stem cell and early differentiation markers. (A and B) Rabbit embryos expressed both pluripotent markers (Oct4 and Nanog) and early differentiation markers (Cdx2, trophoblast-specific transcript; Gata4, early endodermal transcript). The number of cDNA target molecules was calculated by comparing with the standard curve generated from serial dilutions of primer-specific DNA probes generated from cDNA plasmid clones. Ocyt, oocytes; 1-cell, 1-cell-stage embryos; 3.5d, 3.5 dpc embryos; 4.5d, 4.5 dpc embryos; $6 \mathrm{~d}, 6$ dpc embryos; $7 \mathrm{~d}, 7 \mathrm{dpc}$ embryos. performed immunohistological analysis of the $6 \mathrm{dpc}$ stage rabbit embryos. Laser scanning microscope (LSM) confocal microscope visualization demonstrated the Em-specific expression of OCT4 and Tr-specific expression of CDX2 in the $6 \mathrm{dpc}$ rabbit embryos (Fig. 7A and B).

\section{miRNA expression in rabbit ES-like cells}

Subsequent to the ocu-miR-290 and ocu-miR-302 cluster expression analysis during rabbit embryonic development, we explored the expression analysis of both miRNA families in rabbit ES-like cells. We compared the miRNA expression level in attached ICM (ICM of attached blastocyst stage embryos to the mouse feeder layer) and second, third, fourth, and fifth passages of rabbit ES-like cells (Fig. 7). The expression of the ocu-miR-290 cluster and ocu-miR-512-5p was not considerable in rabbit ES-like cells compared with their high expression level during early embryogenesis. ocu-miR-290-5p, ocu-miR-292-3p, and ocu-miR-294-3p were dramatically downregulated after the second passage compared with the attached ICM by 24.3-, 14.3-, and 9.75-fold changes respectively. However, the downregulation of ocu-miR-512-5p was not significant (about 2.1-fold) in contrast to the ocu-miR-290 family. The second and third passages of rabbit ES-like cells showed nearly the same expression level of ocu-miR290-5p, ocu-miR-292-3p, and ocu-miR-294-3p, but the expression of ocu-miR-512-5p was diminished by about 2.3-fold. The expression of the ocu-miR-290 family and ocu-miR-512-5p was reduced after the third passage up to the fifth passage of rabbit ES-like cells (Fig. 8A). Unlike the ocu-miR-290 family, the ocu-miR-302 cluster was highly expressed in the early passages of rabbit ES-like cells. ocu-miR-302a-3p, ocu-miR-302b-3p, and ocumiR-367-3p exhibited upregulation in the second passage of rabbit ES-like cells compared with the attached ICM (9.8-, 10.3-, and 12.2-fold respectively). The expression of ocu-miR-302a-3p, ocu-miR-302b-3p, and ocu-miR-367-3p was significantly elevated by 4-, $4.2-$, and 6.7 -fold changes in the third passage of rabbit ES-like cells compared with the second passage. Likewise, both ocu-miR-302a-3p and ocu-miR-302b-3p showed a significant increase in their expression level by the fourth passage, but ocu-miR-367-3p was downregulated. By the fifth passage, ocu-miR-302a-3p and ocu-miR-367-3p were substantially downregulated, whereas the expression of ocu-miR-302b stayed at the same level (Fig. 8B). The rabbit ES-like cells expressed both Oct4 and Nanog transcripts at a high level, reflecting their pluripotent state; however, their expression was significantly diminished by the third passage. There was an expression of the $\mathrm{Cdx} 2$ transcript, which might be related to the cells derived from the Tr. We could also detect a very low level of Gata4 expression in rabbit ES-like cells correlated with some 
A
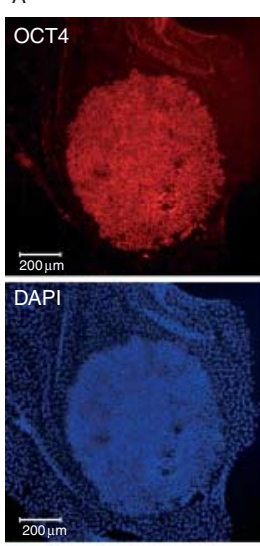

OCT4/DAPI

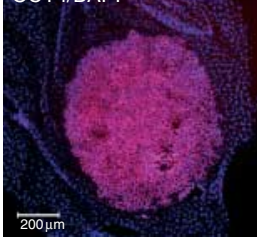

$6 \mathrm{~d}$

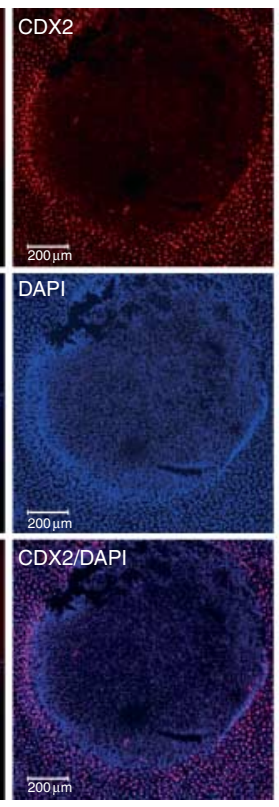

$6 \mathrm{~d}$
C

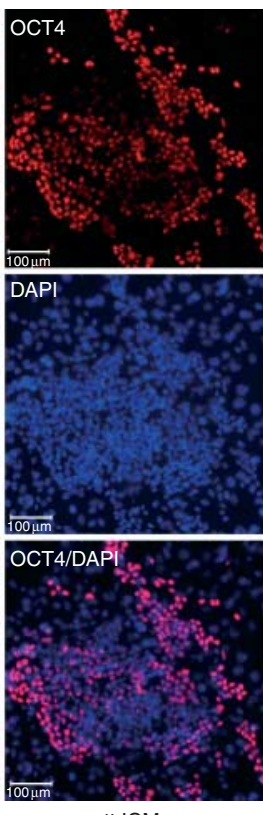

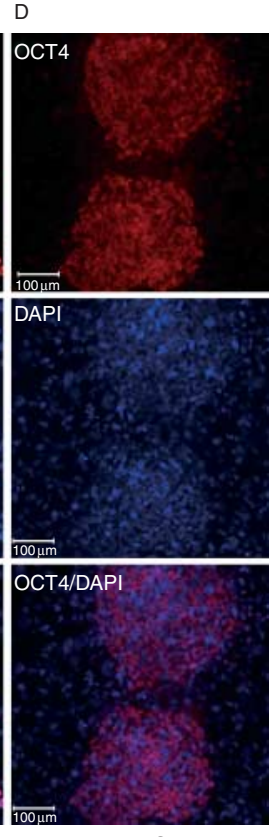

Figure 7 Immunofluorescent detection of OCT4 and CDX2 in rabbit embryos and ES-like cells. (A and B) At the protein level, CDX2 was expressed in rabbit trophoblast cells at the $6 \mathrm{dpc}$ embryonic stage (6d), while OCT4 expression was embryoblast-cell-specific. (C and D). ICM attached to the feeder layer (att.ICM) and pluripotent rabbit ES-likecolonies (rabES) at the third passage expressed OCT4. Images were captured using LSM confocal microscopy. Scale bars represent 100 and $200 \mu \mathrm{m}$.

differentiated cells (Fig. 8C). The immunohistological analysis underlined the expression of OCT4 in rabbit ES-like cells and the ICM attached to the feeder layer (Fig. 7C and D).

\section{Lefty is post-transcriptionally targeted by ocu-miR-302a in rabbit ES-like cells}

We chose to predict the putative targets of ocu-miR-302a miRNA from the miR-302 family based on the fact that all $-3 p$ mature miR-302s share the same seed sequence (Supplementary Table 3, see section on supplementary data given at the end of this article) by which miRNA binds to the 3'UTR of its target mRNAs. Therefore, they may target the same mRNAs (Bartel 2004). LEFTY inhibits the expression of TGF $\beta /$ Activin/Nodal family proteins and is the main antagonist of Nodal signaling (Tabibzadeh \& Hemmati-Brivanlou 2006). There is evidence that TGF $\beta /$ Activin/Nodal signaling through Smad2/3 is necessary for the maintenance of pluripotency in human ESCs (James et al. 2005, Vallier et al. 2005, Bendall et al. 2007, Barroso-delJesus et al. 2009, Montes et al. 2009, Ramos-Mejia et al. 2010). It has also been demonstrated that $L E F T Y$ is negatively modulated by miR-302s in human ESCs (Barroso-deljesus et al. 2011). Based on this evidence, we first analyzed whether ocu-miR-302a could physically interact with Lefty. The rabbit Lefty cDNA sequences available in databases do not contain the $3^{\prime}$ UTRs; hence, the region coding for the $3^{\prime}$ UTR was identified in the genomic sequence of chromosome 16 by similarity search against human LEFTY2 mRNA (NM_003240.3). Sequence analysis of the predicted potential $3^{\prime} U T R$ of rabbit Lefty revealed the presence of two putative target sites for ocu-miR-302a (Fig. 9A). Interestingly, one of the putative target sites (at position 47874528; Fig. 9A) within the predicted rabbit Lefty $3^{\prime}$ UTR was conserved between humans and rabbits (data are not shown). In order to validate the bioinformatic predictions, we transiently transfected rabbit ES-like cells (second passage) with the anti-miR302a inhibitor. Mature miR-302a levels were decreased in anti-miR-302a-transfected rabbit ES-like cells since the anti-miR inhibitors bind irreversibly to miRNAs and inhibit endogenous miRNA molecules (data not shown). The quantitative real-time PCR analysis showed a significant dose-dependent increase in the expression level of Lefty mRNA in anti-miR-302a-transfected rabbit ES-like cells compared with the untransfected control rabbit ES-like cells (Fig. 9B). The rabbit ES-like cells transfected with $100 \mathrm{nM}$ anit-miR-302a exhibited the highest level of expression for Lefty compared with the control ES-like cells by a 3.5-fold change. Likewise, Lefty was upregulated in rabbit ES-like cells treated with 50 and $30 \mathrm{nM}$ anti-miR-302a in contrast to the control ES-like cells by 2.8- and 2.3-fold changes respectively (Fig. 9B).

In summary, we identified all miR-302 cluster members, three miRNAs of the mmu-miR-290 cluster and three 


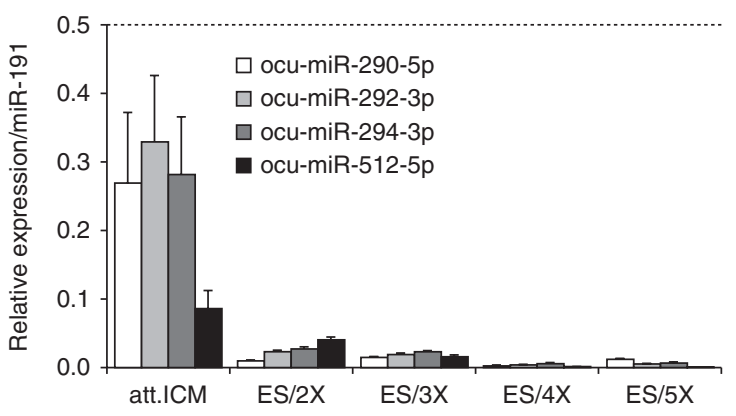

B
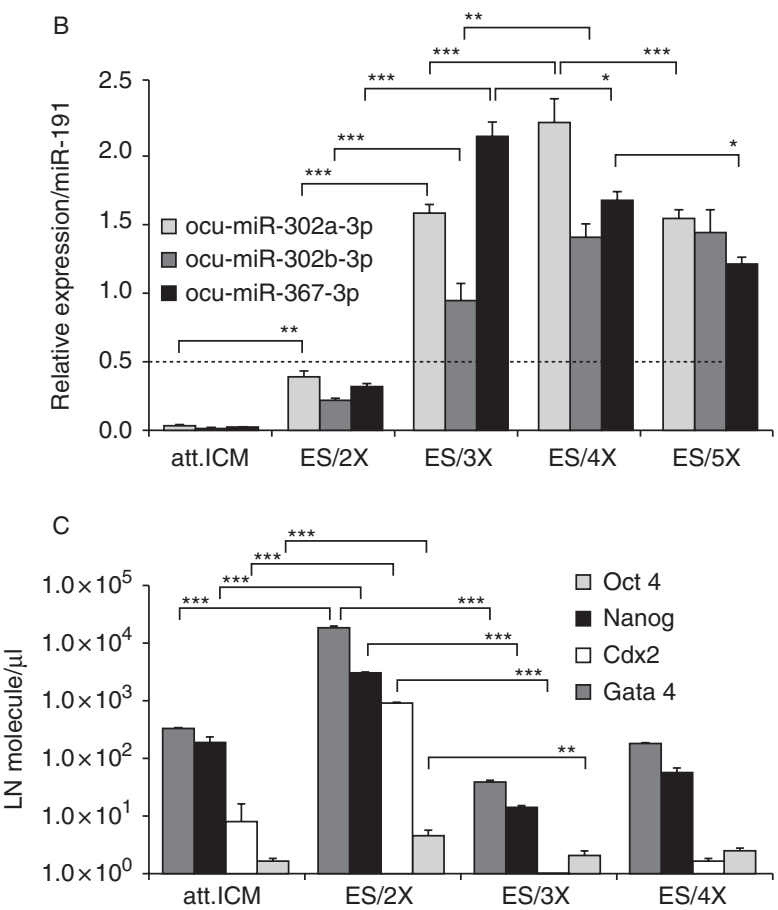

Figure 8 miRNA expression profile in rabbit ES-like cells. (A) ocu-miR290 family and ocu-miR-512-5pexpression was very low throughout rabbit ES-like cell early passages. (B) In contrast, the ocu-miR-302 cluster was expressed at a high level in rabbit ES-like cells. miRNA expression was calculated relative to ocu-miR-191-5p and normalized to the 7 dpc miRNA level. (C) Rabbit ES-like cells expressed pluripotent markers (Oct4 and Nanog) at a high level. Cdx2 and Gata4 expression might be related to trophoblast-derived cells. The number of cDNA target molecules was calculated by comparison with the standard curve generated from serial dilutions of primer-specific DNA probes generated from CDNA plasmid clones. att.ICM: ICM attached to the feeder layer; ES/2X, ES/3X, ES/4X, and ES/5X: second, third, fourth, and fifth passages of rabbit ES-like cells respectively. The asterisks indicate statisticallysignificant differences: ${ }^{*} P<0.05$; ${ }^{*} P<0.02$; and $* * * P<0.001$.

miRNAs of the human C19MC cluster in rabbit pluripotent cells. We propose that the ocu-miR-302 cluster is characteristic of rabbit ES-like cells, whereas ocu-miR290 members play an important role during rabbit early embryogenesis. We also suggested that ocu-miR-512 might have a regulatory role to maintain hypoblast- and Tr-specific mRNAs and proteins. Furthermore, we identified a potential target, Lefty, for ocu-miR-302a and showed that the expression level of Lefty was increased by ocu-miR-302a inhibition in rabbit ES-like cells.

\section{Discussion}

By applying the SOLiD deep-sequencing technique, we report here for the first time, to our knowledge, the miRNA expression profile during early rabbit embryonic development and in ES-like cells. SOLiD sequencing provides a powerful screening method, enabling the simultaneous sequencing of up to millions of DNA or RNA molecules to discover novel miRNAs. The highthroughput sequencing approach allowed us to identify rabbit-specific miRNAs, which have not yet been annotated, and enabled a semi-quantitative estimation of the relative expression level of ocu-miRNAs. We could identify a total of 1693 expressing rabbit miRNAs based on the comparison of the obtained sequence reads with the known hsa-miRNA, mmu-miRNA, and btamiRNA databases (miRBase). The degree of homology of the identified rabbit miRNAs and the number of similar miRNAs to known hsa-miRNAs were higher than known mouse and bta-miRNAs.

Recently, the laboratory rabbit has become one of the most often used experimental models for human health due to its higher similarities with respect to human early development and stem cell biology (Fischer et al. 2012) than the laboratory mouse which does not represent all the crucial phenomena in early mammalian development and stemness status (Berg et al. 2011). Our objective was to identify and characterize ESC-specific miRNAs and miRNA clusters in rabbit ES-like cells, which represented high read numbers based on small RNA library sequencing. rabESCs have been generated and described by several groups (Wang et al. 2007a, Catunda et al. 2008, Honda et al. 2008, 2009, Intawicha et al. 2009, Zakhartchenko et al. 2011); however, fully functional rabESC lines have not yet been established. These generated rabESCs expressed in vitro markers of pluripotency and showed a normal karyotype. Recently, Zakhartchenko et al. (2011) obtained a chimera from a rabESC line, but with a low efficiency. While the existing rabESC lines are not definitive functional ESCs, we aimed to detect and characterize ESC-specific miRNAs of the early steps of rabESC line establishment and their embryonic founder cell population of attached ICM clumps and embryonic discs. miRNAs are essential for early stages of embryonic development and the critical role of miRNAs starts from the first cell division (Tang et al. 2007). Hence, we also aimed to profile the expression pattern of ESC-specific miRNAs of progressive stages of rabbit preimplantation embryonic development, which may play an important role in the establishment and maintenance of pluripotent progenitor cells. On the other hand, the rabbit can be a relevant model to study human embryogenesis, because of its 


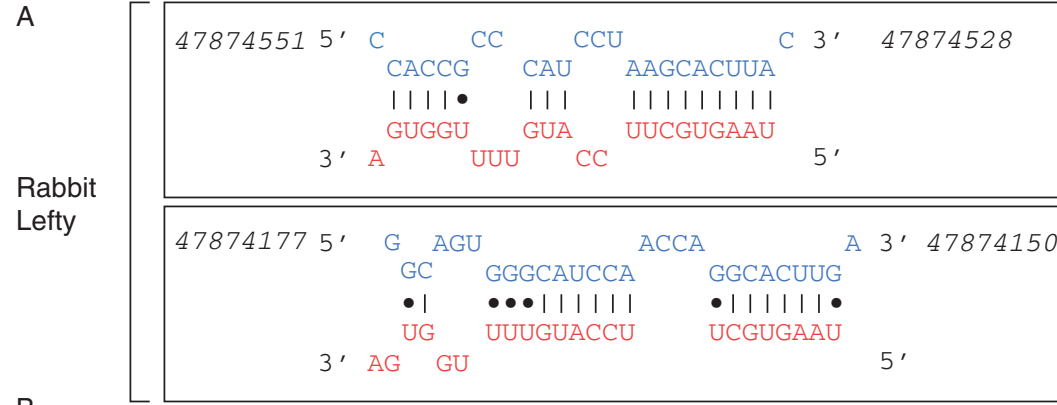

B

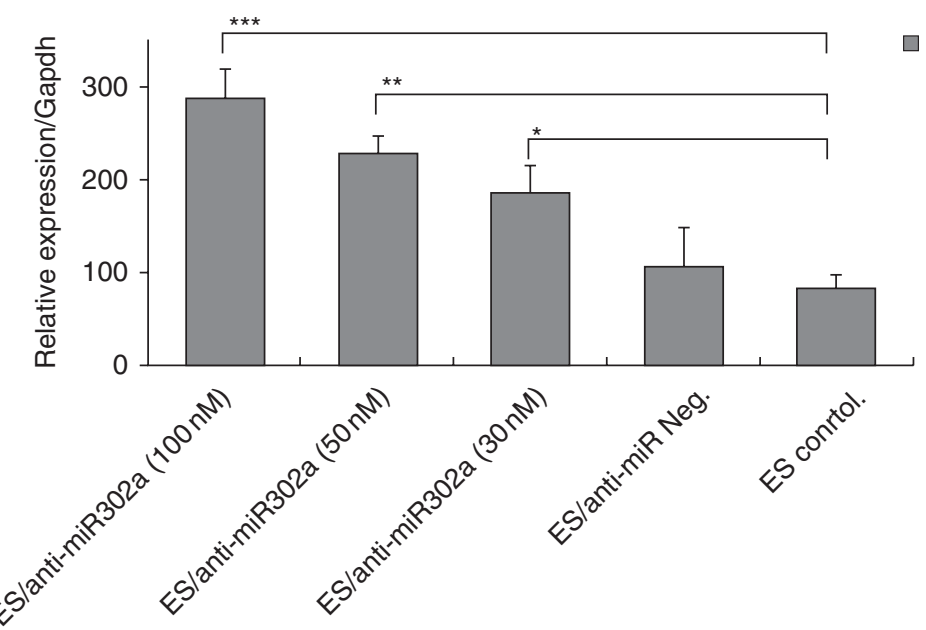

Figure 9 Functional validation of ocu-miR-302a revealed Lefty mRNA as a putative target. (A) Predicted miRNA-target interactions between miR-302a and the putative $3^{\prime}$ UTR of rabbit Lefty mRNA. Two putative ocu-miR-302a binding sites could be predicted downstream from the proteincoding region (on the negative genomic strand at positions $47874528-47874551$ and 47874150 47874177). The sequence of ocu-miR-302a is shown in red and the sequence of putative binding sites within Lefty $3^{\prime}$ UTR is shown in blue. The dashes indicate Watson-Crick base pairs and the dots indicate Wobble base pairs. (B) Rabbit ES-like cells were transiently transfected with the anti-miR-302a inhibitor (100, 50, and $30 \mathrm{nM})$. Lefty mRNA expression was assessed by quantitative real-time PCR, $48 \mathrm{~h}$ after transfection. Lefty was upregulated in a dose-dependent manner upon ocu-miR-302a inhibition in rabbit ES-like cells. The mRNA expression of anti-miR-302a-transfected cells was calculated relative to Gapdh and normalized against the $6 \mathrm{dpc}$ mRNA level. The asterisks indicate statistically significant differences: ${ }^{*} P<0.05$; $* * P<0.02$; and ${ }^{* * *} P<0.001$. higher similarity to human compared with rodents. The rabbit has a common characteristic of non-imprinted early expression of Xist and the delay in X-linked gene inactivation (Okamoto et al. 2011), and a flat-shaped embryonic disc with two layers of the hypoblast and epiblast in the gastrulation stage (Viebahn 1999) and epiblast establishment. Lining up with the earlier data on ESC-specific miRNAs in other species, all miR-302 cluster members (Houbaviy et al. 2003, Suh et al. 2004), some from the mouse miR-290 cluster (ocu-miR290-5p, ocu-miR-292-3p, and ocu-miR-294-3p; Houbaviy et al. 2003, 2005) and three miRNAs of the human C19MC cluster (ocu-miR-512, ocu-miR-498, and ocu-miR-520e; Houbaviy et al. 2003, Bentwich et al. 2005, Bar et al. 2008, Bortolin-Cavaille et al. 2009), were identified in rabbit pluripotent cells.

We found that the ocu-miR-302 cluster is highly similar to its human homolog both in mature and premiRNA sequence levels and in the identical linear order arrangement on its corresponding chromosome (Supplementary Figure 4, see section on supplementary data given at the end of this article). The expression of ocumiR-302 cluster members began at the $3.5 \mathrm{dpc}$ early blastocyst stage and exhibited a high expression level in rabbit ES-like cells (Figs 4 and 8B). Moreover, Oct4, Sox2, and Nanog binding sites, which are conserved regions in humans, mice, primates, birds, and other mammals (Card et al. 2008), were detected in the putative promoter region of the ocu-miR-302 cluster (Fig. 2). Our results underlined the fact that the ocu-miR302 cluster is ESC-specific, like in human ESCs, and can play a crucial role in the maintenance of rabbit stem cell pluripotency and self-renewal. Even though miR-367 had a different seed sequence, its expression is required for miR-302/367-mediated reprogramming and the activation of POU5F1 gene expression (Anokye-Danso et al. 2011); hence, we performed the expression analysis of ocu-miR-367 too. The expression of ocumiR-367 followed the same expression pattern as other members of the cluster during embryonic development and in rabbit ES-like cells.

The ocu-miR-290 cluster comprises only three mature miRNAs, ocu-miR-290-5p, ocu-miR-292-3p, and ocumiR-294-3p, indicating a low level of evolutionary conservation with its mouse homologous cluster. Surprisingly, 5' ocu-miR-290 together with 3' ocu-miR-292 line up in a single pre-miRNA (pre-miR-290/292), whereas the mmu-miR-290 cluster codes for three premiRNAs (pre-miR-290, pre-miR-291a, and pre-miR-292) in the same genomic region.

Furthermore, ocu-miR-512, ocu-miR-520e, and ocu-miR-498 are located in close proximity to the ocu-miR-290 cluster on contig chrUN0226 similar to the human homolog of the mmu-miR-290 cluster and hsa-miR-371 cluster (Supplementary Figure 5, see section on supplementary data given at the end of this 
article). Based on the sequence comparison and repeat analysis, we previously suggested that miR-290-291a was the ancestor of the miR-290 cluster, which gave rise to other members of the cluster through a duplication process (Lichner et al. 2011). It was also proposed that, most probably, hsa-miR-371 was derived from miR-290, while hsa-miR-371 itself is the possible origin of hsa-miR-512. Taken together, we speculate that all six rabbit miRNAs that are located on contig chrUN0226 (ocu-miR-290-5p, ocu-miR-292-2p, ocu-miR-294-3p, ocu-miR-512, ocu-miR-520e, and ocu-miR-498) might be evolved from the same ancestor through duplications. This hypothesis implies that these rabbit miRNAs recapitulate the evolution of human homologs.

The expression of the ocu-miR-290 cluster was initiated in the 4-cell-stage rabbit embryos, as reported earlier in the case of mouse embryos (Tang et al. 2007, Viswanathan et al. 2009), and steadily increased through the blastocyst stage (Fig. 3). Its expression was considerably downregulated at the $6 \mathrm{dpc}$ stage and was remarkably low in rabbit ES-like cells (Figs 3 and $8 \mathrm{~A}$ ). Presumably, the role of the ocu-miR-290 cluster becomes less critical for rabESC maintenance due to its low level of expression in contrast to its higher expression level during early rabbit embryonic development. Similar to mouse embryos (Tang et al. 2007, Svoboda \& Flemr 2010), a low level of maternal ocumiR-290 was detected in rabbit oocytes and a de novo expression of ocu-miR-290 cluster members began in the 1- and 2-cell-stage embryos. Taken together, these data lead us to speculate that the ocu-miR-290 cluster might play an essential role during early rabbit embryogenesis, which is consistent with the notion that knockout of the mmu-miR-290 cluster leads to early embryonic lethality (Medeiros et al. 2011).

In order to gain a comprehensive overview of ESCspecific miRNA expression, we summarized the observed changes in the expression of ocu-miR-302 and ocu-miR-290 clusters during early embryonic development and early passages of rabbit ES-like cells (Fig. 10). We observed the highest expression of the ocumiR-290 cluster at the $3.5 \mathrm{dpc}$ embryonic stage, while the ocu-miR-302 cluster expression began at this embryonic stage and increased through the blastocyst stage. It seems that the $3.5 \mathrm{dpc}$ stage might be a crucial time point of embryonic development, where ocu-miR290 and ocu-miR-302 expressions are evidently altered. It is also tempting to speculate that the expression of these two clusters is regulated directly or indirectly by each other's expression level. It has recently been described that PSCs in the 'naive' state represented by murine ESCs and the 'primed' state represented by murine epiblast stem cells (EpiSCs) and human ESCs (Nichols \& Smith 2009) display a distinct miRNA expression profile (Jouneau et al. 2012). Murine ESCs predominantly express the miR-290 cluster, whereas human ESCs and EpiSCs display predominant expression
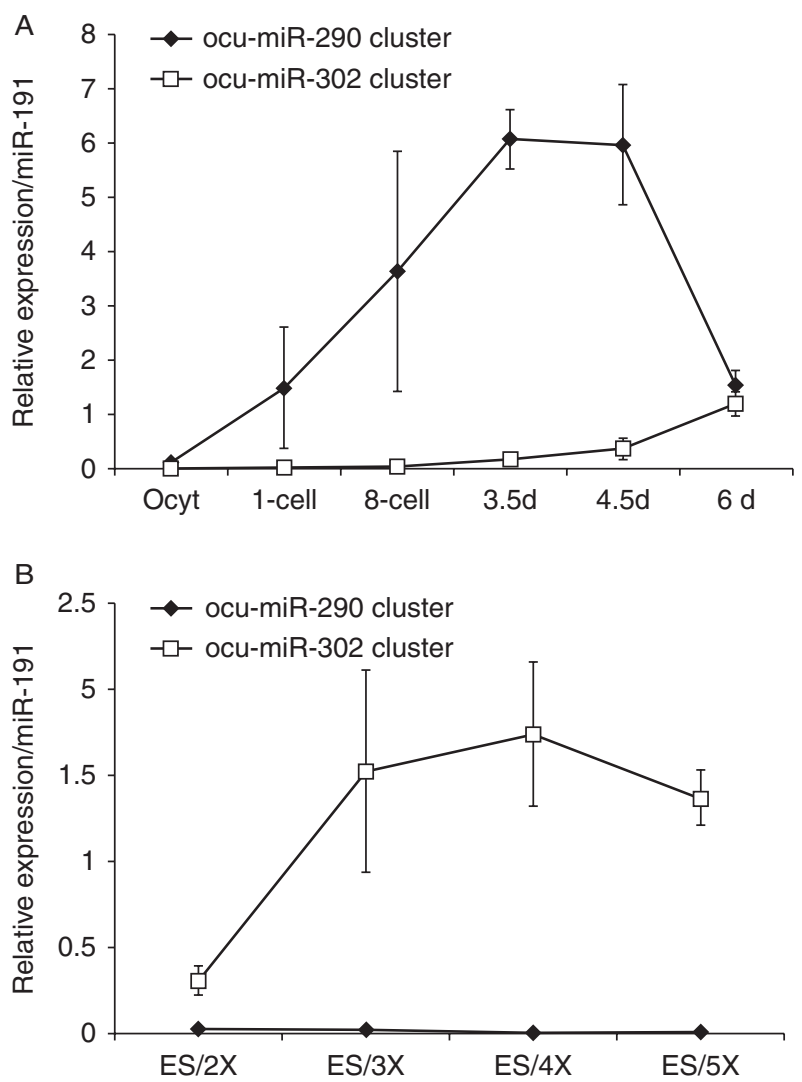

Figure 10 Stem-cell-specific miRNAs are differentially expressed during rabbit embryonic development and in ES-like cell colonies. Summary of the observed changes in ocu-miR-302 and ocu-miR-290 cluster expression during early embryonic development (A) and in early passages of rabbit ES-like cells (B). The highest level of ocu-miR-290 was found at the $3.5 \mathrm{dpc}$ embryonic stage, while the ocu-miR-302 cluster began to be expressed in this time window. Ocyt, oocytes; 1-cell, 1-cell-stage embryos; 8-cell, 8-cell-stage embryos; 3.5d, $3.5 \mathrm{dpc}$ embryos; 4.5d, 4.5 dpc embryos; 6d, $6 \mathrm{dpc}$ embryos; ES/2X, ES/3X, $\mathrm{ES} / 4 \mathrm{X}$, and $\mathrm{ES} / 5 \mathrm{X}$, second, third, fourth, and fifth passages of rabbit ES-like cells respectively.

of the miR-302 cluster (Jouneau et al. 2012). The high expression level of the ocu-miR-302 cluster compared with the low expression level of the ocu-miR-290 cluster in rabbit ES-like cells might reflect their primed state. Our current experiments aimed to improve the culture conditions in order to obtain rabESCs in the naive state.

The differential expression of ocu-miR-302 cluster and ocu-miR-512 miRNA was observed in Tr and Em cells. The higher expression of the ocu-miR-302 cluster in the Em compared with the $\mathrm{Tr}$ indicated the pluripotent characteristics of the Em. However, the expression of ocu-miR-512 appeared in the 8-cell-stage embryos and increased in Tr cells. C19MC, the largest hsa-miRNA gene cluster, is extensively expressed in the placenta and human ESCs (Bentwich et al. 2005, Bar et al. 2008, Cao et al. 2008, Bortolin-Cavaille et al. 2009). Recent studies have shown that C19MC miRNAs are predominantly expressed in primary human Tr cells (Donker et al. 2012, 
Morales-Prieto et al. 2012). Our results showed a high expression level of ocu-miR-512 in the $\mathrm{Tr}$ and a diminished expression level through the rabbit ES-like passages. Furthermore, the abundant expression of ocu-miR-512-5p in the hypoblast and $\operatorname{Tr}$ (Fig. 5C), the embryonal cell types that contribute to the extra-embryonic tissues, suggests that ocu-miR-512 may play a role in the modulation of hypoblast- and Tr-specific mRNAs and proteins.

In order to investigate the biological function of the newly identified rabbit miRNAs, we attempted to identify the putative ocu-miR-302a mRNA target. Considering the low level of ocu-miR-290 cluster expression in rabbit ES-like cells, we decided to predict the putative target of ocu-miR-302a miRNA that was highly expressed in rabbit ES-like cells. Two putative target sites for ocu-miR-302a were identified within the predicted $3^{\prime}$ UTR of the rabbit Lefty gene. One of the putative target sites was conserved between humans and rabbits, which may suggest a functional role for this site through the miRNA-target interaction. Transient inhibition of ocu-miR-302a miRNA in rabbit ES-like cells has allowed us to identify Lefty as a direct target of ocumiR-302a (Fig. 9), underlining earlier findings in human ESCs (Barroso-delJesus et al. 2011). LEFTY is the main antagonist of Nodal signaling and inhibits the expression of TGF $\beta /$ Activin/Nodal family proteins (Tabibzadeh \& Hemmati-Brivanlou 2006). Subsequently, TGF $\beta /$ Activin/ Nodal signaling maintains the pluripotency of human ESCs through Smad2/3 (James et al. 2005, Vallier et al. 2005, Bendall et al. 2007, Barroso-delJesus et al. 2009, Montes et al. 2009, Ramos-Mejia et al. 2010). In addition, all $-3 p$ mature ocu-miR-302s share the same seed sequence; hence, they may target the same mRNAs. We thus propose that the ocu-miR-302 family negatively modulates Lefty mRNA expression in rabbit ES-like cells and maintains their pluripotency through targeting the signaling pathways.

miRNAs have emerged as key regulators in the maintenance of ESCs and early embryonic development. In this study, we present a comprehensive miRNA profile in rabbit preimplantation embryonic development and rabbit ES-like cells. We identified the ocu-miR-302 and ocu-miR-290 clusters and three members of the human C19MC cluster in rabbit embryos and ES-like cells. Our results demonstrate that the expression of ocu-miR-290 cluster members might be crucial during rabbit early embryonic development, while ocu-miR-302 cluster expression is more rabbit ES-like-cell-specific. We also identified Lefty as a direct target of ocu-miR-302a.

\section{Materials and Methods}

\section{Animals}

New Zealand white rabbits (Tetrabbit Ltd, Kartal, Hungary) were used for all experiments, which were conducted in accordance with the guidelines of the Animal Care and Ethics Committee of the Agricultural Biotechnology Center (Ref No. 767/001/2003) and complied with the Hungarian Code of Practice for the Care and Use of Animals for Scientific Purposes, including conditions for animal welfare and handling.

\section{Embryo collection}

New Zealand white rabbits were superovulated with PMSG (30 IU/kg; Invert, Boxmeer, The Netherlands) and hCG (45 IU/kg; Ferring Pharmaceutical, Budapest, Hungary). Embryos were collected at 1-, 2-, 4-, and 8-cell stages, and in $2.5,3.5,4.5,6,7$, and $14 \mathrm{dpc}$ embryos and $14 \mathrm{dpc}$ embryo germinal ridges containing PGCs. Likewise, oocytes were collected after the removal of cumulus cells with $0.03 \%$ hyaluronidase (Sigma). To investigate cell-specific gene expression in the $\mathrm{Tr}$ and $\mathrm{Em}$ and its two cell layers (hypoblast and epiblast), the zona pellucida of $6 \mathrm{dpc}$ embryos was mechanically removed without losing track of the dorsal (epiblast) and ventral (hypoblast) sides of the embryonic disc. The embryonic discs (composed of Em cells) were microdissected from the $\mathrm{Tr}$ under a stereomicroscope, and then the embryonic discs were oriented and tungsten needles were used to remove the hypoblast from the epiblast (Puschel et al. 2010). The isolated Em, hypoblast, epiblast, and Tr of blastocysts were stored separately at $-80^{\circ} \mathrm{C}$.

\section{Cell culture}

The zona pellucida of $4.5 \mathrm{dpc}$ rabbit embryos was removed by treatment with $0.5 \%$ pronase (Sigma-Aldrich) in PBS. The zona-pellucida-free embryos were cultured on mitomycin $\mathrm{C}$ $(10 \mathrm{mg} / \mathrm{ml}$; Sigma-Aldrich) by treating MEFs in basic ESC culture medium (Catunda et al. 2008) supplemented with 15\% serum replacement (Invitrogen) instead of fetal bovine serum used in the original protocol. After embryo attachment, the fresh medium was changed every day and the passages were performed every 5-7 days using accutase (Invitrogen, Life Technologies) to disaggregate the cells.

\section{RNA isolation}

Total RNA was isolated from rabbit oocytes, embryos, ES-like cells, and different tissues with TRIzol reagent (Invitrogen, Life Technologies) according to the manufacturer's instructions.

\section{SOLiD sequencing and small RNA analysis}

Total RNA from 3.5, 4.5, 6, 7, and $14 \mathrm{dpc}$ rabbit embryos, rabbit PGCs of 14 days embryo, rabEF, rabESCs (20 passages), and MEF were processed into sequencing libraries using the Small RNA Expression Kit (SREK, Applied Biosystems). Due to low RNA concentration, 3.5 and $4.5 \mathrm{dpc}$ embryos were excluded from the sequencing program. Libraries were amplified onto beads using emulsion PCR, deposited on slides, and sequenced using the SOLiD 3 System (Applied Biosystems) at the Institute for Plant Genomics, Human Biotechnology and 
Bioenergy, Bay Zoltán Foundation for Applied Research, Szeged, Hungary. The data files obtained from SOLiD sequencing and associated metadata are submitted using SRA Webin (http://www.ebi.ac.uk/ena/data/view/ERP002216). SOLiD data were first analyzed by the SOLiD System Small RNA Analysis Pipeline Tool (RNA2MAP, version 0.5). Annotation of sequences was performed on the basis of similarity to known human, bta, and mmu-miRNA sequences downloaded from miRBase (Released 17: March 2011; http://www.mirbase. org/). To obtain the nucleotide sequences of rabbit miRNAs, color-space SOLiD reads matching one of the known hsamiRNAs, mmu-miRNAs, and bta-mature miRNAs were converted to nucleotide sequences and their consensus was generated after multiple alignment.

\section{Sequence analysis}

Sequences were obtained from the miRBase (http://www. mirbase.org/) and Ensembl databases (http://www.ensembl. org). To analyze sequence similarities and the mature structure of miRNAs, local alignment was carried out using the BLAST2SEQ program at NCBI (http://blast.ncbi.nlm.nih.gov/) and BLAT Search against the rabbit genome assembly (oryCun2) at UCSC (http://genome.ucsc.edu/).

Known human and mouse pre-miRNAs were used as query sequences to identify putative pre-miRNA sequences in the rabbit. Then, the obtained putative pre-miRNAs were subjected to the RNAshapes tool (http://bibiserv.techfak.uni-bielefeld.de/ rnashapes/) and the results were obtained in BMP graphics containing the secondary structure with MFE.

\section{Real-time quantitative PCR}

Mature miRNA quantification was performed with a twostep protocol including RT with miRNA-specific primers (Supplementary Table 6, see section on supplementary data given at the end of this article) using the TaqMan MicroRNA Reverse Transcription Kit, followed by quantitative real-time PCR with TaqMan MicroRNA Assays-TM (Supplementary Table 6) using the TaqMan Gene Expression Master Mix. For mRNA quantification, the extracted total RNA samples were reverse transcribed into cDNA, using a High Capacity cDNA Reverse Transcription Kit. The synthesized cDNAs were subjected to quantitative real-time PCR using the SYBR Green PCR Master Mix as a double-stranded DNA-specific fluorescent dye with rabbit specific primer sets (Invitrogen, Life Technologies; Supplementary Table 7). All reagents were purchased from Applied Biosystems, Life Technologies and reaction protocols were carried out according to the manufacturer's instructions. The reactions for both miRNA and mRNA were automated by the Eppendorf Mastercycler ep realplex ${ }^{4}$.

Fold change was calculated based on the $\Delta \Delta C$ t method normalized to miR-191 (for miRNA expression analysis) and Gapdh (for mRNA expression analysis; Navarrete Santos et al. 2008). Indeed, the number of target cDNA molecules was calculated by comparison with the standard curve generated from serial dilutions $\left(10,10^{2}, 10^{3}, 10^{4}, 10^{5}, 10^{6}, 10^{7}\right.$, and $10^{8}$ molecules $/ \mu \mathrm{l}$ ) of primer-specific DNA probes generated from
cDNA plasmid clones. The analysis was performed using GenEx qPCR data analysis software by MultiD (http://www. multid.se).

For each sample, the signal was averaged over replicates. Each biological replicate of embryos consisted of a pool of staged embryos (Supplementary Table 8, see section on supplementary data given at the end of this article). Results are expressed as mean \pm s.D. A one-way ANOVA test (GenEx software) followed by the Tukey-Kramer test was used to document any statistically significant difference between multiple groups. A probability level of $P<0.05$ was considered to be significant.

\section{Immunocytochemical staining}

Embryos were fixed in 4\% paraformaldehyde (Sigma-Aldrich) in PBS at room temperature for $10 \mathrm{~min}$ and washed in PBS. For blocking, PBS containing 0.1\% BSA, 0.01\% Tween-20, and $\%$ donkey serum was used for $30 \mathrm{~min}$. Samples were incubated with an appropriate amount of primary antibodies overnight at $4{ }^{\circ} \mathrm{C}$ and then with secondary antibodies for $1 \mathrm{~h}$ at room temperature. The following primary antibodies were used: Oct4 (ab27985, 1:100; Abcam, Cambridge, UK) and Cdx2 (ab15258, 1:100; Abcam). Secondary-fluorochrome-conjugated antibodies (Jackson ImmunoResearch Laboratories, West Grove, PA, USA) were diluted 1:400 in blocking buffer. Nuclear staining was performed by embedding the cells in DAPI containing Vectashield mounting medium ( $\mathrm{H}-1200$; Vector Laboratories, Burlingame, CA, USA). Samples were visualized under the LSM confocal microscope (Carl Zeiss, Göttingen, Germany).

\section{Rabbit BAC library screening}

A BAC clone containing the rabbit miR-290 gene cluster was isolated from a rabbit genomic BAC library that has been constructed from high-molecular-weight DNA prepared from white blood cells of a New Zealand rabbit (Rogel-Gaillard et al. 2001). Screening was performed based on the PCR screening method using three pairs of rabbit specific primers: rab-miR290-FW/RV, rab-miR294-FW/RV, and rab-nlrp12-FW/ RV (Supplementary Table 9, see section on supplementary data given at the end of this article). The selected BAC clone was subjected to sequencing with a set of forward and reverse primers (Supplementary Table 9).

\section{Identifying putative target sites of ocu-miR-302a}

The 3'UTR sequences were missing from many predicted rabbit Ensembl transcripts; thus, BLASTN (Altschul et al. 1997) similarity searches with full-length human cDNAs were carried out at Ensembl (http://www.ensembl.org) to find the regions covering the $3^{\prime} U T R s$ in the rabbit genome. Putative miRNA target sites and miRNA-mRNA duplexes were then predicted using the online RNAhybrid program (http:// bibiserv.techfak.uni-bielefeld.de/rnahybrid/; Rehmsmeier et al. 2004) 


\section{Transfection of rabbit ES-like cells with the anti-miR-302a inhibitor}

Rabbit ES-like cells (second passage) in a 96-well plate were transfected with the anti-miR-302a inhibitor (100, 50, and $30 \mathrm{nM}$; AM10936) and its corresponding negative control (50 nM; AM17010) using the siPORT NeoFX transfection agent for $48 \mathrm{~h}$ according to the manufacturer's instructions. For global mRNA analysis, $48 \mathrm{~h}$ after transfection, the cells were harvested in TRIzol and subjected to real-time PCR analysis. All oligonucleotides and reagents were purchased from Applied Biosystems/Ambion, USA.

\section{Supplementary data}

This is linked to the online version of the paper at http://dx.doi. org/10.1530/REP-12-0259.

\section{Declaration of interest}

The authors declare that there is no conflict of interest that could be perceived as prejudicing the impartiality of the research reported.

\section{Funding}

This research was funded by grants Plurabbit: OMFB-0013000131/2010 ANR-NKTH/09-GENM-010-01 to Z Bósze; OTKA K77913 and MÖB-47-1/2009 to E Gócza.

\section{Acknowledgements}

We would like to thank Dr C Rogel-Gaillard (LREG, INRA, France) for the valuable help in the rabbit BAC library screening and providing the BAC clone and Dr Alexander V Makarevich, Dr Peter Chrenek and Jaro Slamecka, Animal Production Research Centre (Nitra, Slovak Republic) for their assistance in LSM confocal microscopy. We also would like to thank Dr Zsuzsanna Lichner (Keenan Research Centre, Toronto, Canada) for her careful review of the manuscript and advice, Dr Oana I Gavriliuc (Victor Babes University of Medicine and Pharmacy, Romania) for her assistance in the miRNA inhibition experiment, Mária Gróf for her technical assistance with the embryo collection and cell culturing, Dr Hamid Heidari (Eppendorf, Austria) for his technical support on the real-time PCR and Omid H Muhammad for his assistance with the literature search.

\section{References}

Altschul SF, Madden TL, Schaffer AA, Zhang J, Zhang Z, Miller W \& Lipman DJ 1997 Gapped BLAST and PSI-BLAST: a new generation of protein database search programs. Nucleic Acids Research 25 3389-3402. (doi:10.1093/nar/25.17.3389)

Anokye-Danso F, Trivedi CM, Juhr D, Gupta M, Cui Z, Tian Y, Zhang Y, Yang W, Gruber PJ, Epstein JA et al. 2011 Highly efficient miRNAmediated reprogramming of mouse and human somatic cells to pluripotency. Cell Stem Cell 8 376-388. (doi:10.1016/j.stem.2011. 03.001)
Bar M, Wyman SK, Fritz BR, Qi J, Garg KS, Parkin RK, Kroh EM, Bendoraite A, Mitchell PS, Nelson AM et al. 2008 MicroRNA discovery and profiling in human embryonic stem cells by deep sequencing of small RNA libraries. Stem Cells 26 2496-2505. (doi:10.1634/stemcells. 2008-0356)

Baranyi M, Hiripi L, Szabo L, Catunda AP, Harsanyi I, Komaromy P \& Bosze Z 2007 Isolation and some effects of functional, low-phenylalanine kappa-casein expressed in the milk of transgenic rabbits. Journal of Biotechnology 128 383-392. (doi:10.1016/j.jbiotec.2006. 10.016)

Barroso-delJesus A, Romero-Lopez C, Lucena-Aguilar G, Melen GJ, Sanchez L, Ligero G, Berzal-Herranz A \& Menendez P 2008 Embryonic stem cell-specific miR302-367 cluster: human gene structure and functional characterization of its core promoter. Molecular and Cellular Biology 28 6609-6619. (doi:10.1128/MCB.00398-08)

Barroso-delJesus A, Lucena-Aguilar G \& Menendez P 2009 The miR302-367 cluster as a potential stemness regulator in ESCs. Cell Cycle 8 394-398. (doi:10.4161/cc.8.3.7554)

Barroso-delJesus A, Lucena-Aguilar G, Sanchez L, Ligero G, GutierrezAranda I \& Menendez P 2011 The Nodal inhibitor Lefty is negatively modulated by the microRNA miR-302 in human embryonic stem cells. FASEB Journal 25 1497-1508. (doi:10.1096/fj.10-172221)

Bartel DP 2004 MicroRNAs: genomics, biogenesis, mechanism, and function. Cell 116 281-297. (doi:10.1016/S0092-8674(04)00045-5)

Bendall SC, Stewart MH, Menendez P, George D, Vijayaragavan K, Werbowetski-Ogilvie T, Ramos-Mejia V, Rouleau A, Yang J, Bosse M et al. 2007 IGF and FGF cooperatively establish the regulatory stem cell niche of pluripotent human cells in vitro. Nature 448 1015-1021. (doi:10.1038/nature06027)

Benetti R, Gonzalo S, Jaco I, Munoz P, Gonzalez S, Schoeftner S, Murchison E, Andl T, Chen T, Klatt P et al. 2008 A mammalian microRNA cluster controls DNA methylation and telomere recombination via Rbl2-dependent regulation of DNA methyltransferases. Nature Structural \& Molecular Biology 15 998. (doi:10.1038/nsmb0908-998b)

Bentwich I, Avniel A, Karov Y, Aharonov R, Gilad S, Barad O, Barzilai A, Einat P, Einav U, Meiri E et al. 2005 Identification of hundreds of conserved and nonconserved human microRNAs. Nature Genetics 37 766-770. (doi:10.1038/ng1590)

Berg DK, Smith CS, Pearton DJ, Wells DN, Broadhurst R, Donnison M \& Pfeffer PL 2011 Trophectoderm lineage determination in cattle. Developmental Cell 20 244-255. (doi:10.1016/j.devcel.2011.01.003)

Bernstein E, Kim SY, Carmell MA, Murchison EP, Alcorn H, Li MZ, Mills AA, Elledge SJ, Anderson KV \& Hannon GJ 2003 Dicer is essential for mouse development. Nature Genetics 35 215-217. (doi:10.1038/ng1253)

Bortolin-Cavaille ML, Dance M, Weber M \& Cavaille J 2009 C19MC microRNAs are processed from introns of large Pol-II, non-proteincoding transcripts. Nucleic Acids Research 37 3464-3473. (doi:10.1093/ nar/gkp205)

Cao H, Yang CS \& Rana TM 2008 Evolutionary emergence of microRNAs in human embryonic stem cells. PLOS ONE 3 e2820. (doi:10.1371/journal. pone.0002820)

Card DA, Hebbar PB, Li L, Trotter KW, Komatsu Y, Mishina Y \& Archer TK 2008 Oct4/Sox2-regulated miR-302 targets cyclin D1 in human embryonic stem cells. Molecular and Cellular Biology 28 6426-6438. (doi:10.1128/MCB.00359-08)

Catunda AP, Gocza E, Carstea BV, Hiripi L, Hayes H, Rogel-Gaillard C, Bertaud M \& Bosze Z 2008 Characterization, chromosomal assignment, and role of LIFR in early embryogenesis and stem cell establishment of rabbits. Cloning and Stem Cells 10 523-534. (doi:10.1089/clo.2008. 0023)

Chen C, Ridzon D, Lee CT, Blake J, Sun Y \& Strauss WM 2007 Defining embryonic stem cell identity using differentiation-related microRNAs and their potential targets. Mammalian Genome 18 316-327. (doi:10. 1007/s00335-007-9032-6)

Donker RB, Mouillet JF, Chu T, Hubel CA, Stolz DB, Morelli AE \& Sadovsky Y 2012 The expression profile of C19MC microRNAs in primary human trophoblast cells and exosomes. Molecular Human Reproduction 18 417-424. (doi:10.1093/molehr/gas013)

Fischer B, Chavatte-Palmer P, Viebahn C, Navarrete Santos A \& Duranthon V 2012 Rabbit as a reproductive model for human health. Reproduction 144 1-10. (doi:10.1530/REP-12-0091) 
Grishok A, Pasquinelli AE, Conte D, Li N, Parrish S, Ha I, Baillie DL, Fire A, Ruvkun G \& Mello CC 2001 Genes and mechanisms related to RNA interference regulate expression of the small temporal RNAs that control C. elegans developmental timing. Cell 106 23-34. (doi:10.1016/S00928674(01)00431-7)

Gu P, Reid JG, Gao X, Shaw CA, Creighton C, Tran PL, Zhou X, Drabek RB, Steffen DL, Hoang DM et al. 2008 Novel microRNA candidates and miRNA-mRNA pairs in embryonic stem (ES) cells. PLoS ONE 3 e2548. (doi:10.1371/journal.pone.0002548)

Han ZS, Li QW, Zhang ZY, Yu YS, Xiao B, Wu SY, Jiang ZL, Zhao HW, Zhao R \& Li J 2008 Adenoviral vector mediates high expression levels of human lactoferrin in the milk of rabbits. Journal of Microbiology and Biotechnology 18 153-159.

Hiripi L, Makovics F, Halter R, Baranyi M, Paul D, Carnwath JW, Bosze Z \& Niemann H 2003 Expression of active human blood clotting factor VIII in mammary gland of transgenic rabbits. DNA and Cell Biology 22 41-45. (doi:10.1089/104454903321112488)

Honda A, Hirose M, Inoue K, Ogonuki N, Miki H, Shimozawa N, Hatori M, Shimizu N, Murata T, Katayama K et al. 2008 Stable embryonic stem cell lines in rabbits: potential small animal models for human research. Reproductive BioMedicine Online 17 706-715. (doi:10.1016/S14726483(10)60320-3)

Honda A, Hirose M \& Ogura A 2009 Basic FGF and Activin/Nodal but not LIF signaling sustain undifferentiated status of rabbit embryonic stem cells. Experimental Cell Research 315 2033-2042. (doi:10.1016/j.yexcr. 2009.01.024)

Houbaviy HB, Murray MF \& Sharp PA 2003 Embryonic stem cell-specific microRNAs. Developmental Cell 5 351-358. (doi:10.1016/S15345807(03)00227-2)

Houbaviy HB, Dennis L, Jaenisch R \& Sharp PA 2005 Characterization of a highly variable eutherian microRNA gene. RNA 11 1245-1257. (doi:10.1261/rna.2890305)

Intawicha P, Ou YW, Lo NW, Zhang SC, Chen YZ, Lin TA, Su HL, Guu HF, Chen MJ, Lee KH et al. 2009 Characterization of embryonic stem cell lines derived from New Zealand white rabbit embryos. Cloning and Stem Cells 11 27-38. (doi:10.1089/clo.2008.0040)

James D, Levine AJ, Besser D \& Hemmati-Brivanlou A 2005 TGF $\beta /$ activin/nodal signaling is necessary for the maintenance of pluripotency in human embryonic stem cells. Development 132 1273-1282. (doi:10.1242/dev.01706)

Jouneau A, Ciaudo C, Sismeiro O, Brochard V, Jouneau L, VandormaelPournin S, Coppee JY, Zhou Q, Heard E, Antoniewski C et al. 2012 Naive and primed murine pluripotent stem cells have distinct miRNA expression profiles. RNA 18 253-264. (doi:10.1261/rna.028878.111)

Judson RL, Babiarz JE, Venere M \& Blelloch R 2009 Embryonic stem cell-specific microRNAs promote induced pluripotency. Nature Biotechnology 27 459-461. (doi:10.1038/nbt.1535)

Kanellopoulou C, Muljo SA, Kung AL, Ganesan S, Drapkin R, Jenuwein T, Livingston DM \& Rajewsky K 2005 Dicer-deficient mouse embryonic stem cells are defective in differentiation and centromeric silencing. Genes and Development 19 489-501. (doi:10.1101/gad.1248505)

Kang SJ \& Grossniklaus HE 2011 Rabbit model of retinoblastoma. Journal of Biomedicine \& Biotechnology 2011394730.

Kelley K \& Lin SL 2012 Induction of somatic cell reprogramming using the microRNA miR-302. Progress in Molecular Biology and Translational Science 111 83-107. (doi:full text)

Ketting RF, Fischer SE, Bernstein E, Sijen T, Hannon GJ \& Plasterk RH 2001 Dicer functions in RNA interference and in synthesis of small RNA involved in developmental timing in C. elegans. Genes and Development 15 2654-2659. (doi:10.1101/gad.927801)

Kuo CH, Deng JH, Deng Q \& Ying SY 2012 A novel role of miR-302/367 in reprogramming. Biochemical and Biophysical Research Communications 417 11-16. (doi:10.1016/j.bbrc.2011.11.058)

Laurent LC, Chen J, Ulitsky I, Mueller FJ, Lu C, Shamir R, Fan JB \& Loring JF 2008 Comprehensive microRNA profiling reveals a unique human embryonic stem cell signature dominated by a single seed sequence. Stem Cells 26 1506-1516. (doi:10.1634/stemcells.2007-1081)

Li MA \& He L 2012 microRNAs as novel regulators of stem cell pluripotency and somatic cell reprogramming. Bioessays 34 670-680. (doi:10.1002/ bies.201200019)
Li Z, Yang CS, Nakashima K \& Rana TM 2011 Small RNA-mediated regulation of iPS cell generation. EMBO Journal 30 823-834. (doi:10.1038/emboj.2011.2)

Liao B, Bao X, Liu L, Feng S, Zovoilis A, Liu W, Xue Y, Cai J, Guo X, Qin B et al. 2011 MicroRNA cluster 302-367 enhances somatic cell reprogramming by accelerating a mesenchymal-to-epithelial transition. Journal of Biological Chemistry 286 17359-17364. (doi:10.1074/jbc.C111.235960)

Lichner Z, Pall E, Kerekes A, Pallinger E, Maraghechi P, Bosze Z \& Gocza E 2011 The miR-290-295 cluster promotes pluripotency maintenance by regulating cell cycle phase distribution in mouse embryonic stem cells. Differentiation 81 11-24. (doi:10.1016/j.diff.2010.08.002)

Lim LP, Lau NC, Garrett-Engele P, Grimson A, Schelter JM, Castle J, Bartel DP, Linsley PS \& Johnson JM 2005 Microarray analysis shows that some microRNAs downregulate large numbers of target mRNAs. Nature 433 769-773. (doi:10.1038/nature03315)

Lin GP, Jiang T, Hu XB, Qiao XH \& Tuo QH 2007 Effect of Siraitia grosvenorii polysaccharide on glucose and lipid of diabetic rabbits induced by feeding high fat/high sucrose chow. Experimental Diabetes Research 2007 67435. (doi:10.1155/2007/67435)

Lin SL, Chang DC, Lin CH, Ying SY, Leu D \& Wu DT 2011 Regulation of somatic cell reprogramming through inducible mir-302 expression. Nucleic Acids Research 39 1054-1065. (doi:10.1093/nar/gkq850)

Lipchina I, Studer L \& Betel D 2012 The expanding role of miR-302-367 in pluripotency and reprogramming. Cell Cycle 11 1517-1523. (doi:10. 4161/cc.19846)

Luningschror P, Stocker B, Kaltschmidt B \& Kaltschmidt C 2012 miR-290 cluster modulates pluripotency by repressing canonical NF-kappaB signaling. Stem Cells 30 655-664. (doi:10.1002/stem.1033)

Marson A, Levine SS, Cole MF, Frampton GM, Brambrink T, Johnstone S, Guenther MG, Johnston WK, Wernig M, Newman J et al. 2008 Connecting microRNA genes to the core transcriptional regulatory circuitry of embryonic stem cells. Cell 134 521-533. (doi:10.1016/j.cell. 2008.07.020)

Medeiros LA, Dennis LM, Gill ME, Houbaviy H, Markoulaki S, Fu D, White AC, Kirak O, Sharp PA, Page DC et al. 2011 Mir-290-295 deficiency in mice results in partially penetrant embryonic lethality and germ cell defects. PNAS 108 14163-14168. (doi:10.1073/pnas. 1111241108)

Mineno J, Okamoto S, Ando T, Sato M, Chono H, Izu H, Takayama M, Asada K, Mirochnitchenko O, Inouye M et al. 2006 The expression profile of microRNAs in mouse embryos. Nucleic Acids Research $\mathbf{3 4}$ 1765-1771. (doi:10.1093/nar/gkl096)

Miyoshi N, Ishii H, Nagano $H$, Haraguchi N, Dewi DL, Kano $Y$, Nishikawa S, Tanemura M, Mimori K, Tanaka F et al. 2011 Reprogramming of mouse and human cells to pluripotency using mature microRNAs. Cell Stem Cell 8 633-638. (doi:10.1016/j.stem.2011.05. 001)

Montes R, Ligero G, Sanchez L, Catalina P, de la Cueva T, Nieto A, Melen GJ, Rubio R, Garcia-Castro J, Bueno C et al. 2009 Feeder-free maintenance of hESCs in mesenchymal stem cell-conditioned media: distinct requirements for TGF- $\beta$ and IGF-II. Cell Research 19 698-709. (doi:10.1038/cr.2009.35)

Morales-Prieto DM, Chaiwangyen W, Ospina-Prieto S, Schneider U, Herrmann J, Gruhn B \& Markert UR 2012 MicroRNA expression profiles of trophoblastic cells. Placenta 33 725-734. (doi:10.1016/j.placenta. 2012.05.009)

Murchison EP, Partridge JF, Tam OH, Cheloufi S \& Hannon GJ 2005 Characterization of Dicer-deficient murine embryonic stem cells. PNAS 102 12135-12140. (doi:10.1073/pnas.0505479102)

Narayanaswamy M, Wright KC \& Kandarpa K 2000 Animal models for atherosclerosis, restenosis, and endovascular graft research. Journal of Vascular and Interventional Radiology 11 5-17. (doi:10.1016/S10510443(07)61271-8)

Navarrete Santos A, Ramin N, Tonack S \& Fischer B 2008 Cell lineagespecific signaling of insulin and insulin-like growth factor I in rabbit blastocysts. Endocrinology 149 515-524. (doi:10.1210/en.2007-0821)

Nichols J \& Smith A 2009 Naive and primed pluripotent states. Cell Stem Cell 4 487-492. (doi:10.1016/j.stem.2009.05.015)

Okamoto I, Patrat C, Thepot D, Peynot N, Fauque P, Daniel N, Diabangouaya P, Wolf JP, Renard JP, Duranthon V et al. 2011 Eutherian mammals use diverse strategies to initiate X-chromosome inactivation during development. Nature 472 370-374. (doi:10.1038/nature09872) 
Puschel B, Bitzer E \& Viebahn C 2010 Live rabbit embryo culture. Cold Spring Harbor Protocols 2010 pdb prot5352.

Ramin N, Thieme R, Fischer S, Schindler M, Schmidt T, Fischer B \& Navarrete Santos A 2010 Maternal diabetes impairs gastrulation and insulin and IGF-I receptor expression in rabbit blastocysts. Endocrinology 151 4158-4167. (doi:10.1210/en.2010-0187)

Ramos-Mejia V, Melen GJ, Sanchez L, Gutierrez-Aranda I, Ligero G, Cortes JL, Real PJ, Bueno C \& Menendez P 2010 Nodal/Activin signaling predicts human pluripotent stem cell lines prone to differentiate toward the hematopoietic lineage. Molecular Therapy 18 2173-2181. (doi:10.1038/mt.2010.179)

Rehmsmeier M, Steffen P, Hochsmann M \& Giegerich R 2004 Fast and effective prediction of microRNA/target duplexes. RNA 10 1507-1517. (doi:10.1261/rna.5248604)

Reinhart BJ, Slack FJ, Basson M, Pasquinelli AE, Bettinger JC, Rougvie AE, Horvitz HR \& Ruvkun G 2000 The 21-nucleotide let-7 RNA regulates developmental timing in Caenorhabditis elegans. Nature 403 901-906. (doi:10.1038/35002607)

Ripplinger CM, Li W, Hadley J, Chen J, Rothenberg F, Lombardi R, Wickline SA, Marian AJ \& Efimov IR 2007 Enhanced transmural fiber rotation and connexin 43 heterogeneity are associated with an increased upper limit of vulnerability in a transgenic rabbit model of human hypertrophic cardiomyopathy. Circulation Research 101 1049-1057. (doi:10.1161/CIRCRESAHA.107.161240)

Rogel-Gaillard C, Piumi F, Billault A, Bourgeaux N, Save JC, Urien C, Salmon J \& Chardon P 2001 Construction of a rabbit bacterial artificial chromosome (BAC) library: application to the mapping of the major histocompatibility complex to position 12q.1.1. Mammalian Genome 12 253-255. (doi:10.1007/s003350010260)

Sinkkonen L, Hugenschmidt T, Berninger P, Gaidatzis D, Mohn F, ArtusRevel CG, Zavolan M, Svoboda P \& Filipowicz W 2008 MicroRNAs control de novo DNA methylation through regulation of transcriptional repressors in mouse embryonic stem cells. Nature Structural \& Molecular Biology 15 259-267. (doi:10.1038/nsmb.1391)

Strauss WM, Chen C, Lee CT \& Ridzon D 2006 Nonrestrictive developmental regulation of microRNA gene expression. Mammalian Genome 17 833-840. (doi:10.1007/s00335-006-0025-7)

Strozzi F, Mazza R, Malinverni R \& Williams JL 2009 Annotation of 390 bovine miRNA genes by sequence similarity with other species. Animal Genetics 40 125. (doi:10.1111/j.1365-2052.2008.01780.x)

Subramanyam D, Lamouille S, Judson RL, Liu JY, Bucay N, Derynck R \& Blelloch R 2011 Multiple targets of miR-302 and miR-372 promote reprogramming of human fibroblasts to induced pluripotent stem cells. Nature Biotechnology 29 443-448. (doi:10.1038/nbt.1862)

Suh MR, Lee Y, Kim JY, Kim SK, Moon SH, Lee JY, Cha KY, Chung HM, Yoon HS, Moon SY et al. 2004 Human embryonic stem cells express a unique set of microRNAs. Developmental Biology 270 488-498. (doi:10.1016/j.ydbio.2004.02.019)

Svoboda P \& Flemr M 2010 The role of miRNAs and endogenous siRNAs in maternal-to-zygotic reprogramming and the establishment of pluripotency. EMBO Reports 11 590-597. (doi:10.1038/embor.2010.102)

Tabibzadeh S \& Hemmati-Brivanlou A 2006 Lefty at the crossroads of "stemness" and differentiative events. Stem Cells 24 1998-2006. (doi:10.1634/stemcells.2006-0075)

Takahashi K \& Yamanaka S 2006 Induction of pluripotent stem cells from mouse embryonic and adult fibroblast cultures by defined factors. Cell 126 663-676. (doi:10.1016/j.cell.2006.07.024)

Tang F, Kaneda M, O'Carroll D, Hajkova P, Barton SC, Sun YA, Lee C, Tarakhovsky A, Lao K \& Surani MA 2007 Maternal microRNAs are essential for mouse zygotic development. Genes and Development 21 644-648. (doi:10.1101/gad.418707)
Thieme R, Ramin N, Fischer S, Puschel B, Fischer B \& Navarrete Santos A 2012 Gastrulation in rabbit blastocysts depends on insulin and insulinlike-growth-factor 1. Molecular and Cellular Endocrinology $\mathbf{3 4 8}$ 112-119. (doi:10.1016/j.mce.2011.07.044)

Vallier L, Alexander M \& Pedersen RA 2005 Activin/Nodal and FGF pathways cooperate to maintain pluripotency of human embryonic stem cells. Journal of Cell Science 118 4495-4509. (doi:10.1242/jcs.02553)

Viebahn C 1999 The anterior margin of the mammalian gastrula: comparative and phylogenetic aspects of its role in axis formation and head induction. Current Topics in Developmental Biology 46 63-103. (doi:full_text)

Viswanathan SR, Mermel CH, Lu J, Lu CW, Golub TR \& Daley GQ 2009 microRNA expression during trophectoderm specification. PLOS ONE 4 e6143. (doi:10.1371/journal.pone.0006143)

Wang S, Tang X, Niu Y, Chen H, Li B, Li T, Zhang X, Hu Z, Zhou Q \& Ji W 2007 a Generation and characterization of rabbit embryonic stem cells. Stem Cells 25 481-489. (doi:10.1634/stemcells.2006-0226)

Wang Y, Medvid R, Melton C, Jaenisch R \& Blelloch R 2007b DGCR8 is essential for microRNA biogenesis and silencing of embryonic stem cell self-renewal. Nature Genetics 39 380-385. (doi:10.1038/ng1969)

Wang Y, Baskerville S, Shenoy A, Babiarz JE, Baehner L \& Blelloch R 2008 Embryonic stem cell-specific microRNAs regulate the G1-S transition and promote rapid proliferation. Nature Genetics 40 1478-1483. (doi:10.1038/ng.250)

Wightman B, Ha I \& Ruvkun G 1993 Posttranscriptional regulation of the heterochronic gene lin-14 by lin- 4 mediates temporal pattern formation in C. elegans. Cell 75 855-862. (doi:10.1016/0092-8674(93)90530-4)

Winiarska K, Malinska D, Szymanski K, Dudziak M \& Bryla J 2008 Lipoic acid ameliorates oxidative stress and renal injury in alloxan diabetic rabbits. Biochimie 90 450-459. (doi:10.1016/j.biochi.2007.11.010)

Woodruff-Pak DS 2008 Animal models of Alzheimer's disease: therapeutic implications. Journal of Alzheimer's Disease 15 507-521.

Yang WJ, Yang DD, Na S, Sandusky GE, Zhang Q \& Zhao G 2005 Dicer is required for embryonic angiogenesis during mouse development. Journal of Biological Chemistry 280 9330-9335. (doi:10.1074/jbc. M413394200)

Yang CS, Li Z \& Rana TM 2011 microRNAs modulate iPS cell generation. RNA 17 1451-1460. (doi:10.1261/rna.2664111)

Zahn G, Volk K, Lewis GP, Vossmeyer D, Stragies R, Heier JS, Daniel PE Jr, Adamis AP, Chapin EA, Fisher SK et al. 2010 Assessment of the integrin a $5 \beta 1$ antagonist JSM6427 in proliferative vitreoretinopathy using in vitro assays and a rabbit model of retinal detachment. Investigative Ophthalmology \& Visual Science 51 1028-1035. (doi:10.1167/iovs. 09-3575)

Zakhartchenko V, Flisikowska T, Li S, Richter T, Wieland H, Durkovic M, Rottmann O, Kessler B, Gungor T, Brem G et al. 2011 Cell-mediated transgenesis in rabbits: chimeric and nuclear transfer animals. Biology of Reproduction 84 229-237. (doi:10.1095/biolreprod.110.087098)

Zeng F \& Schultz RM 2005 RNA transcript profiling during zygotic gene activation in the preimplantation mouse embryo. Developmental Biology 283 40-57. (doi:10.1016/j.ydbio.2005.03.038)

Zovoilis A, Smorag L, Pantazi A \& Engel W 2009 Members of the miR-290 cluster modulate in vitro differentiation of mouse embryonic stem cells. Differentiation 78 69-78. (doi:10.1016/j.diff.2009.06.003)

Received 6 July 2012

First decision 16 August 2012

Revised manuscript received 9 February 2013

Accepted 19 February 2013 